\title{
SCIAMACHY: Mission Objectives and Measurement Modes
}

\author{
H. Bovensmann, J. P. Burrows, M. Buchwitz, J. Frerick, S. Noël, and V. V. Rozanov \\ Institute of Environmental Physics, University of Bremen, Bremen, Germany \\ K. V. Chance \\ Harvard-Smithsonian Center for Astrophysics, Cambridge, Massachusetts
}

A. P. H. GoEdE

SRON Ruimetonderzoek, Utrecht, the Netherlands

(Manuscript received 5 September 1997, in final form 16 June 1998)

\section{ABSTRACT}

\begin{abstract}
SCIAMACHY (Scanning Imaging Absorption Spectrometer for Atmospheric Chartography) is a spectrometer designed to measure sunlight transmitted, reflected, and scattered by the earth's atmosphere or surface in the ultraviolet, visible, and near-infrared wavelength region $(240-2380 \mathrm{~nm})$ at moderate spectral resolution $(0.2-$ $1.5 \mathrm{~nm}, \lambda / \Delta \lambda \approx 1000-10000)$. SCIAMACHY will measure the earthshine radiance in limb and nadir viewing geometries and solar or lunar light transmitted through the atmosphere observed in occultation. The extraterrestrial solar irradiance and lunar radiance will be determined from observations of the sun and the moon above the atmosphere. The absorption, reflection, and scattering behavior of the atmosphere and the earth's surface is determined from comparison of earthshine radiance and solar irradiance. Inversion of the ratio of earthshine radiance and solar irradiance yields information about the amounts and distribution of important atmospheric constituents and the spectral reflectance (or albedo) of the earth's surface.

SCIAMACHY was conceived to improve our knowledge and understanding of a variety of issues of importance for the chemistry and physics of the earth's atmosphere (troposphere, stratosphere, and mesosphere) and potential changes resulting from either increasing anthropogenic activity or the variability of natural phenomena. Topics of relevance for SCIAMACHY are

- tropospheric pollution arising from industrial activity and biomass burning,

- troposphere-stratosphere exchange processes,

- stratospheric ozone chemistry focusing on the understanding of the ozone depletion in polar regions as well as in midlatitudes, and

- solar variability and special events such as volcanic eruptions, and related regional and global phenomena.

Inversion of the SCIAMACHY measurements enables the amounts and distribution of the atmospheric constituents $\mathrm{O}_{3}, \mathrm{O}_{2}, \mathrm{O}_{2}\left({ }^{1} \Delta\right), \mathrm{O}_{4}, \mathrm{BrO}, \mathrm{OClO}, \mathrm{ClO}, \mathrm{SO}_{2}, \mathrm{H}_{2} \mathrm{CO}, \mathrm{NO}, \mathrm{NO}_{2}, \mathrm{NO}_{3}, \mathrm{CO}, \mathrm{CO}_{2}, \mathrm{CH}_{4}, \mathrm{H}_{2} \mathrm{O}, \mathrm{N}_{2} \mathrm{O}$, and aerosol, as well as knowledge about the parameters pressure $p$, temperature $T$, radiation field, cloud cover, cloudtop height, and surface spectral reflectance to be determined. A special feature of SCIAMACHY is the combined limb-nadir measurement mode. The inversion of the combination of limb and nadir measurements will enable tropospheric column amounts of $\mathrm{O}_{3}, \mathrm{NO}_{2}, \mathrm{BrO}, \mathrm{CO}, \mathrm{CH}_{4}, \mathrm{H}_{2} \mathrm{O}, \mathrm{N}_{2} \mathrm{O}, \mathrm{SO}_{2}$, and $\mathrm{H}_{2} \mathrm{CO}$ to be determined.
\end{abstract}

\section{Introduction}

Large and significant changes in the composition and behavior of the global atmosphere have emphasized the need for global measurements of atmospheric constituents. Examples are (i) the precipitous loss of Antarctic (WMO 1995) and Arctic stratospheric ozone $\left(\mathrm{O}_{3}\right)$ (New-

Corresponding author address: Dr. Heinrich Bovensmann, Institute of Environmental Physics, University of Bremen (FB1), P.O. Box 33 04 40, D-28334 Bremen, Germany.

E-mail: bov@gome5.physik.uni-bremen.de man et al. 1997; Müller et al. 1997) resulting from the tropospheric emission of chlorofluorocarbon compounds (CFCs, halones, and HFCs) (WMO 95); (ii) the global increase of tropospheric $\mathrm{O}_{3}$ (WMO 1995); (iii) the observed increase of tropospheric "greenhouse gases" such as $\mathrm{CO}_{2}, \mathrm{CH}_{4}, \mathrm{~N}_{2} \mathrm{O}$, and $\mathrm{O}_{3}$ (IPCC 1996); and (iv) the potential coupling between polar stratospheric ozone loss and increased greenhouse gas concentrations (Shindell et al. 1998).

To assess the significance of such changes a detailed understanding of the physical and chemical processes controlling the global atmosphere is required. Similarly knowledge about the variability and temporal behavior 
of atmospheric trace gases is necessary to test the predictive ability of the theories currently used to model the atmosphere. Consequently, the accurate assessment of the impact of current and future anthropogenic activity or natural phenomena on the behavior of the atmosphere needs detailed knowledge about the temporal and spatial behavior of several atmospheric trace constituents (gases, aerosol, clouds) on a global scale, including the troposphere.

Over the past two decades pioneering efforts have been made by the scientific community to establish both ground-based networks and satellite projects that will eventually result in an adequate global observing system. Examples of satellite borne elements of such programs are the Solar Backscatter Ultraviolet (SBUV) and Total Ozone Mapping Spectrometer (TOMS) on NASA's Nimbus-7 satellite (Heath et al. 1975); the Stratospheric Aerosol and Gas Experiment (SAGE) (McCormick et al. 1979); the Upper Atmosphere Research Satellite (UARS) (Reber et al. 1993) with the Microwave Limb Sounder (MLS), the Halogen Occultation Experiment (HALOE), the Cryogenic Limb Array Etalon Spectrometer (CLAES), and the Improved Stratospheric and Mesospheric Sounder (ISAMS) instruments on board; and the Second European Remote Sensing satellite (ERS-2), which carries the Global Ozone Monitoring Experiment (GOME) (Burrows et al. 1999). In the near future, several new missions will be launched and will contribute significantly to research in the fields of atmospheric chemistry and physics: NASA's Earth Observing System (EOS) satellites EOS-AM and EOS-CHEM, the Japanese Advanced Earth Observing System (ADEOS), and the European Space Agency's (ESA) Environmental Satellite (ENVISAT).

The Scanning Imaging Absorption Spectrometer for Atmospheric Chartography (SCIAMACHY) is part of the atmospheric chemistry payload onboard ENVISAT being prepared by ESA. Following the call for earth observation instrumentation in the Announcement of Opportunity for the Polar Platform issued by ESA, the SCIAMACHY proposal (Burrows et al. 1988) was submitted to ESA by an international team of scientists led by Principal Investigator J. P. Burrows. After peer review SCIAMACHY was selected as part of the payload for the satellite now known as ENVISAT, which is planned to be launched in 2000 .

The heritage of SCIAMACHY (Burrows et al. 1988) lies in both the ground-based measurements using Differential Optical Absorption Spectroscopy (DOAS) (Brewer et al. 1973; Platt and Perner 1980; Solomon et al. 1987) and previous satellite atmospheric remote sensing missions. SCIAMACHY combines and extends the measurement principles and observational modes of the nadir scattered sunlight measuring instruments SBUV and TOMS (Heath et al. 1975), the solar occultation instrument SAGE (McCormick et al. 1979; Mauldin et al. 1985), and the limb scattered sunlight measuring instrument Solar Mesospheric Explorer (SME)
(Barth et al. 1983) within one instrument. SCIAMACHY measures in the wavelength range from $240 \mathrm{~nm}$ to $2380 \mathrm{~nm}$ the following:

- The scattered and reflected spectral radiance in nadir and limb geometry,

- the spectral radiance transmitted through the atmosphere in solar and lunar occultation geometry, and

- the extraterrestrial solar irradiance and the lunar radiance.

Limb, nadir, and occultation measurements are planned to be made during every orbit. Trace gases, aerosols, clouds, and the surface of the earth modify the light observed by SCIAMACHY via absorption, emission, and scattering processes. Inversion of the radiance and irradiance measurements enables the amounts and distributions of a significant number of constituents to be retrieved from their spectral signatures and is discussed in section 4. Figure 1 shows the wavelength range to be observed by SCIAMACHY and the position of spectral windows where atmospheric constituents are to be retrieved.

SCIAMACHY and GOME, which is a small-scale version of SCIAMACHY (see Burrows et al. 1999 and references therein), represent a new generation of spacebased remote sounding sensors, which rely on and utilize the simultaneous spectrally resolved measurement of light upwelling from the atmosphere to determine amounts of atmospheric constituents.

Using data from GOME, which was launched on board the European Remote Sensing satellite ERS-2 in April 1995, the feasibility of the instrument and retrieval concepts have been successfully demonstrated for nadir observations. The trace gases $\mathrm{O}_{3}, \mathrm{NO}_{2}, \mathrm{BrO}, \mathrm{OClO}$, $\mathrm{SO}_{2}$, and $\mathrm{H}_{2} \mathrm{CO}$ have been observed as predicted (Burrows et al. 1999), and studies of $\mathrm{ClO}, \mathrm{NO}$, and aerosol retrieval are proceeding. The determination of $\mathrm{O}_{3}$ profile information, including tropospheric $\mathrm{O}_{3}$, from GOME measurements (Burrows et al. 1999; Munro et al. 1998; Rozanov et al. 1998) has a large number of potential applications. In addition, the retrieval of tropospheric column information of $\mathrm{SO}_{2}, \mathrm{H}_{2} \mathrm{CO}, \mathrm{NO}_{2}$, and $\mathrm{BrO}$ from GOME measurements was demonstrated (Burrows et al. 1999).

The goal of this paper is to provide a comprehensive overview of the SCIAMACHY mission and instrument, to summarize the retrieval strategies, to report on planned data products and expected data quality, and to demonstrate the range of applications and the potential that lies in the concept of this new generation of hyperspectral UV-VIS-NIR sensors. Section 2 provides details about the targeted constituents. In section 3 the instrument design and observational modes are presented. The proposed retrieval strategies are summarized in section 4. Section 5 focuses on the expected data precision and section 6 summarizes the current status of operational data products. 


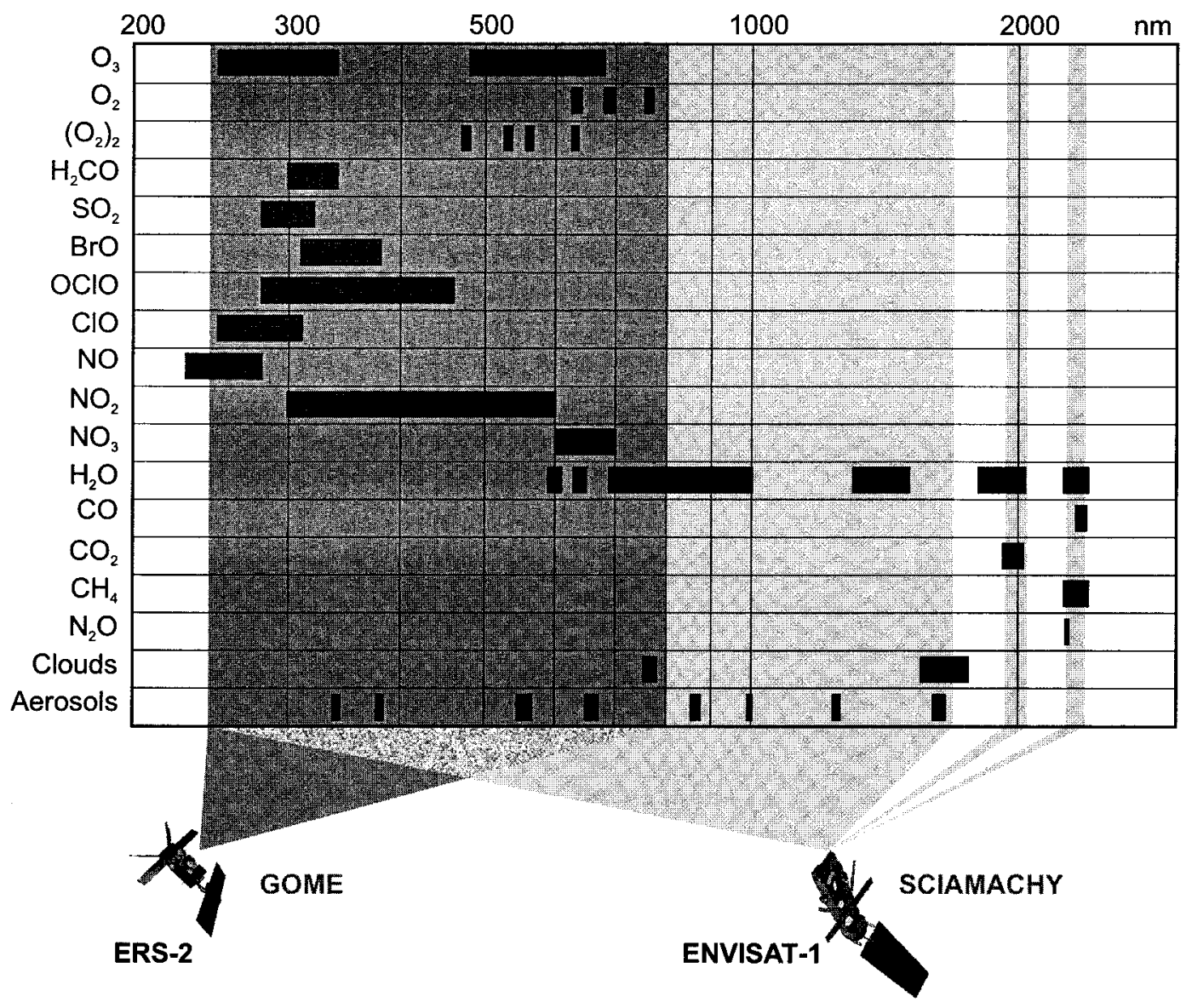

FIG. 1. Wavelength range covered by SCIAMACHY and absorption windows of the targeted constituents.

\section{Scientific objectives and targeted constituents}

The main objective of the SCIAMACHY mission is to improve our knowledge of global atmospheric change and related issues of importance to the chemistry and physics of our atmosphere (cf. WMO 1995 and IPCC 1996) such as

- the impact of tropospheric pollution arising from industrial activity and biomass burning,

- exchange processes between the stratosphere and troposphere,

- stratospheric chemistry in the polar regions (e.g., under "ozone hole" conditions) and at midlatitudes, and

- modulations of atmospheric composition resulting from natural phenomena such as volcanic eruptions, solar output variations (e.g., solar cycle), or solar proton events.

Figure 2 lists the constituents targeted by SCIAMACHY and shows the altitude where measurements are to be made. In Fig. 2, the combined use of nadir and limb measurements is assumed to yield tropospheric amounts of the constituents down to the ground or the cloud top, depending on cloud cover.

\section{a. Tropospheric chemistry}

SCIAMACHY will measure the backscattered sunlight that reaches the earth's surface $(\lambda \geq 280 \mathrm{~nm})$. The retrieval of tropospheric constituents is influenced and limited by clouds. SCIAMACHY is the only atmospheric chemistry sensor on ENVISAT capable of determining trace gases and aerosol abundances in the lower troposphere including the planetary boundary layer under cloud-free conditions. From the SCIAMACHY nadir and limb measurements tropospheric columns of $\mathrm{O}_{3}, \mathrm{NO}_{2}, \mathrm{BrO}, \mathrm{CO}, \mathrm{CH}_{4}, \mathrm{H}_{2} \mathrm{O}, \mathrm{N}_{2} \mathrm{O}, \mathrm{SO}_{2}$, and $\mathrm{H}_{2} \mathrm{CO}$ (cf. Fig. 2) will be retrieved. In addition, surface spectral reflectance, aerosol and cloud parameters (cover and cloud-top height), and the tropospheric flux from 280 to $2380 \mathrm{~nm}$ will be retrieved. These data are required for studies of the oxidizing capacity of the troposphere, photochemical $\mathrm{O}_{3}$ production and destruction, and tropospheric pollution (biomass burning, industrial activities, aircraft).

\section{b. Stratosphere-troposphere exchange}

For the investigation of stratosphere-troposphere exchange (Holton et al. 1995) SCIAMACHY measure- 


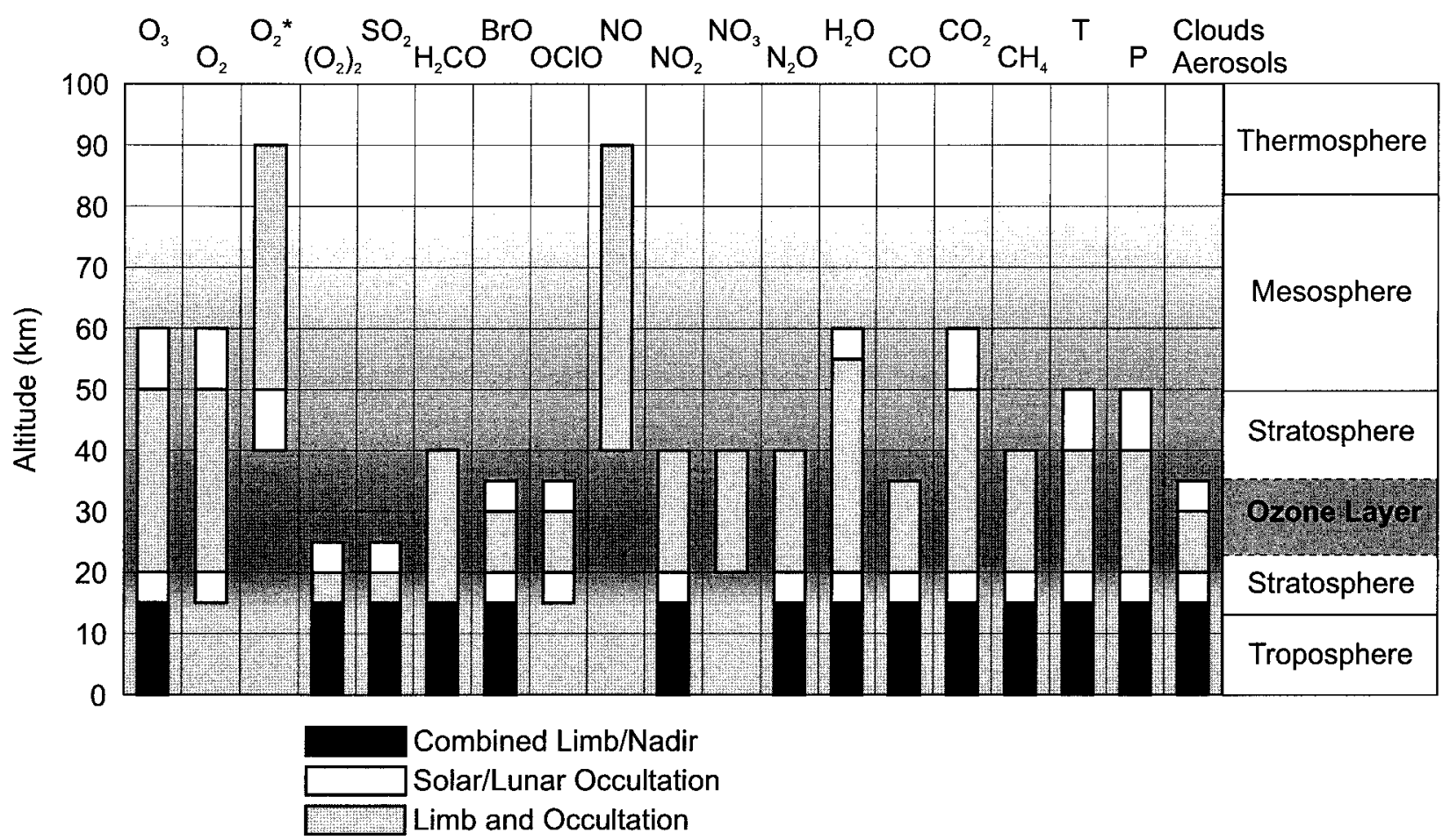

FIG. 2. Altitude ranges of atmospheric constituents targeted by SCIAMACHY. Retrieval from the occultation measurements yields information over a wider altitude range than the limb measurements, due to its higher $\mathrm{S} / \mathrm{N}$ ratio.

ments of the height-resolved profiles of the tracers $\mathrm{O}_{3}$, $\mathrm{H}_{2} \mathrm{O}, \mathrm{N}_{2} \mathrm{O}, \mathrm{CH}_{4}$, and aerosol will be of primary significance. These measurements enable investigations of the downward transport of stratospheric $\mathrm{O}_{3}$ and upward transport of important species (e.g., aerosol, $\mathrm{CH}_{4}, \mathrm{H}_{2} \mathrm{O}$, and $\mathrm{N}_{2} \mathrm{O}$ ). The $\mathrm{CH}_{4}$ and $\mathrm{N}_{2} \mathrm{O}$ molecules are emitted into the planetary boundary layer. Their long tropospheric lifetime results in being transported to the stratosphere, where they are the dominant source of the ozone-destroying $\mathrm{HO}_{x}$ and $\mathrm{NO}_{x}$ radicals. Studies of relatively small-scale features such as tropopause folding at midlatitudes require a high spatial resolution and are unlikely to be unambiguously observed by SCIAMACHY. However, larger-scale stratosphere-troposphere exchange as envisaged by Holton et al. (1995) will be readily observed.

In the neighborhood of the tropopause the different measurements modes of SCIAMACHY will have different vertical and horizontal resolutions. Solar and lunar occultation modes yield measurements with a vertical resolution of $2.5 \mathrm{~km}$ and a horizontal resolution of $30 \mathrm{~km}$ across track, determined by the solar diameter, and extending roughly $400 \mathrm{~km}$ along track. For the limb measurements the geometrical spatial resolution is approximately $3 \mathrm{~km}$ vertically and typically $240 \mathrm{~km}$ horizontally across track, determined by scan speed and integration time, and extending roughly $400 \mathrm{~km}$ along track (see Table 3). More details about the geometrical resolution of the different measurement modes will be given in section $3 b$.

\section{c. Stratospheric chemistry and dynamics}

The study of the stratospheric chemistry and dynamics will utilize the simultaneous retrieval of total columns from nadir measurements and vertical stratospheric profiles from limb and occultation measurements of $\mathrm{O}_{3}, \mathrm{NO}_{2}, \mathrm{BrO}, \mathrm{H}_{2} \mathrm{O}, \mathrm{CO}, \mathrm{CH}_{4}$, and $\mathrm{N}_{2} \mathrm{O}$ (and $\mathrm{OClO}$ and possibly $\mathrm{ClO}$ under ozone hole conditions), as well as aerosol and stratospheric cloud information. Temperature and pressure profiles can be determined from limb and occultation observations of the well-mixed gases $\mathrm{CO}_{2}$ and $\mathrm{O}_{2}$ assuming local thermal equilibrium.

SCIAMACHY will be making measurements when halogen loading of the stratosphere maximizes around the turn of the century (WMO 1995). It has recently been pointed out by Hofmann (1996) that the springtime polar lower-stratospheric $\mathrm{O}_{3}$, specifically the layer from 12 to $20 \mathrm{~km}$, will be the first region to show a response to the international control measures on chlorofluorocarbon compounds (CFCs) defined in the Montreal Protocol of 1987 and its Copenhagen and London amendments. SCIAMACHY will enable this preposition to be studied in detail.

In general, SCIAMACHY measurements will yield detailed information about the development of strato- 
spheric $\mathrm{O}_{3}$ above the Arctic and Antarctica, the global stratospheric active halogen species $(\mathrm{BrO}, \mathrm{ClO}, \mathrm{OClO})$, and the global $\mathrm{O}_{3}$ budget as a function of the height in the atmosphere. As SCIAMACHY measures simultaneously the backscattered radiation field and constituent profiles, an important objective is to test the accuracy of current stratospheric photochemical models and their predictive capability.

\section{d. Mesospheric chemistry and dynamics}

In the upper stratosphere and lower mesosphere SCIAMACHY measurements yield profiles of $\mathrm{O}_{3}, \mathrm{H}_{2} \mathrm{O}$, $\mathrm{N}_{2} \mathrm{O}, \mathrm{NO}, \mathrm{O}_{2}$, and $\mathrm{O}_{2}\left({ }^{1} \Delta\right)$. These measurements will be used to study the distribution of $\mathrm{H}_{2} \mathrm{O}$ and $\mathrm{O}_{3}$ and their global circulation. There has recently been much discussion of upper-stratospheric and mesospheric chemistry in the context of the "ozone deficit problem" (Crutzen at al. 1995; Summers et al. 1997). It has also been suggested that monitoring of $\mathrm{H}_{2} \mathrm{O}$ in the lower mesosphere may offer an opportunity for the early detection of climate change (Chandra et al. 1997). The $\mathrm{O}_{3}$ destruction by mesospheric and upper-stratospheric NO will be investigated. Finally, the mesospheric source of stratospheric $\mathrm{NO}_{x}$ will be quantified.

In contrast to the retrieval of the majority of trace gases from SCIAMACHY data, $\mathrm{NO}$ and $\mathrm{O}_{2}\left({ }^{1} \Delta\right)$ profiles are to be determined from their emission features rather than their absorptions. Satellite measurements of NO via the $\gamma$-band emission had been demonstrated by SME to determine profile information from the limb scan (Barth et al. 1983, 1988) and by SBUV to determine column amounts above $45 \mathrm{~km}$ from nadir measurements (McPeters 1989). NO can be detected above $40 \mathrm{~km}$ via the emission from the excited $A^{2} \Sigma^{+}$state into the ground state $X^{2} \Pi_{1 / 2,3 / 2}$ (NO $\gamma$-band transitions, 200-300 nm) as determined in a model sensitivity study by Frederick and Abrams (1982). SCIAMACHY will be able to detect several bands in the $240-300-\mathrm{nm}$ spectral region of the $\gamma$-band emissions of NO in limb as well as in nadir observation mode.

$\mathrm{O}_{2}\left({ }^{1} \Delta\right)$ can be detected using its emission around 1.27 $\mu \mathrm{m}$ as shown by results from the SME (Thomas et al. 1984). The combination of height-resolved $\mathrm{O}_{3}, \mathrm{O}_{2}\left({ }^{1} \Delta\right)$, and UV radiance products from SCIAMACHY provides detailed information about the photolysis of $\mathrm{O}_{3}$ in the upper stratosphere and mesosphere. This will provide an excellent opportunity to test our current photochemical knowledge of the mesosphere.

\section{e. Climate research}

For use in climate research, SCIAMACHY measurements will provide the distributions of several important greenhouse gases $\left(\mathrm{O}_{3}, \mathrm{H}_{2} \mathrm{O}, \mathrm{CH}_{4}, \mathrm{~N}_{2} \mathrm{O}\right.$, and $\left.\mathrm{CO}_{2}\right)$, aerosol and cloud data, surface spectral reflectance (280$2380 \mathrm{~nm})$, the incoming solar spectral irradiance and the outgoing spectral radiance $(240-2380 \mathrm{~nm})$, and pro- files of $p$ and $T$ (via $\mathrm{O}_{2}$ and $\mathrm{CO}_{2}$ ). As it is intended that SCIAMACHY observations are to be made for many years, this long-term dataset will provide much unique information useful for the study of the earth-atmosphere system and variations of the solar output and its impact on climate change. To reach continuity with other spectrometers measuring solar spectral irradiance such as SBUV or GOME, it is foreseen that SCIAMACHY will be calibrated with standard methods also applied to the GOME or SBUV calibration (Weber et al. 1998).

\section{The instrument}

Details of the instrument concept and design have been given by Burrows and Chance (1991), Goede et al. (1994), Burrows et al. (1995), and Mager et al. (1997). The design is summarized in the following subsections. Since the development of the design of SCIAMACHY two significant changes have occurred.

1) The original concept (Burrows and Chance 1991; Burrows et al. 1995) used an active Stirling cooler to maintain the infrared detectors of SCIAMACHY at their operational temperature of $150 \mathrm{~K}$. During the development phase it was found that a passive cooler could be used for this purpose. This has the advantage of reducing the electrical power consumption and potentially extending the lifetime of the mission.

2) As an outcome of phase B studies an additional seventh polarization measurement device (PMD), measuring the $45^{\circ}$ component of the incoming radiance, was added to the spectrometer, to improve the radiometric accuracy for the limb mode.

\section{a. Design and performance}

The SCIAMACHY instrument is a passive remote sensing moderate-resolution imaging spectrometer. It comprises a mirror system, a telescope, a spectrometer, and thermal and electronic subsystems. A schematic view of the light path within the instrument is depicted in Fig. 3. The incoming radiation enters the instrument via one of three ports.

1) For nadir measurements the radiation from the earth's scene is directed by the nadir mirror into a telescope (off-axis parabolic mirror), which focuses the beam onto the entrance slit of the spectrometer.

2) For limb and solar/lunar occultation measurements the radiation is reflected by the limb (elevation) mirror to the nadir (azimuth) mirror and then into the telescope, which focuses the beam onto the entrance slit of the spectrometer.

3) For internal and subsolar calibration measurements the radiation of internal calibration light sources or the solar radiation is directed by the nadir mirror into the telescope.

Except for the scan mirrors, all spectrometer parts are 


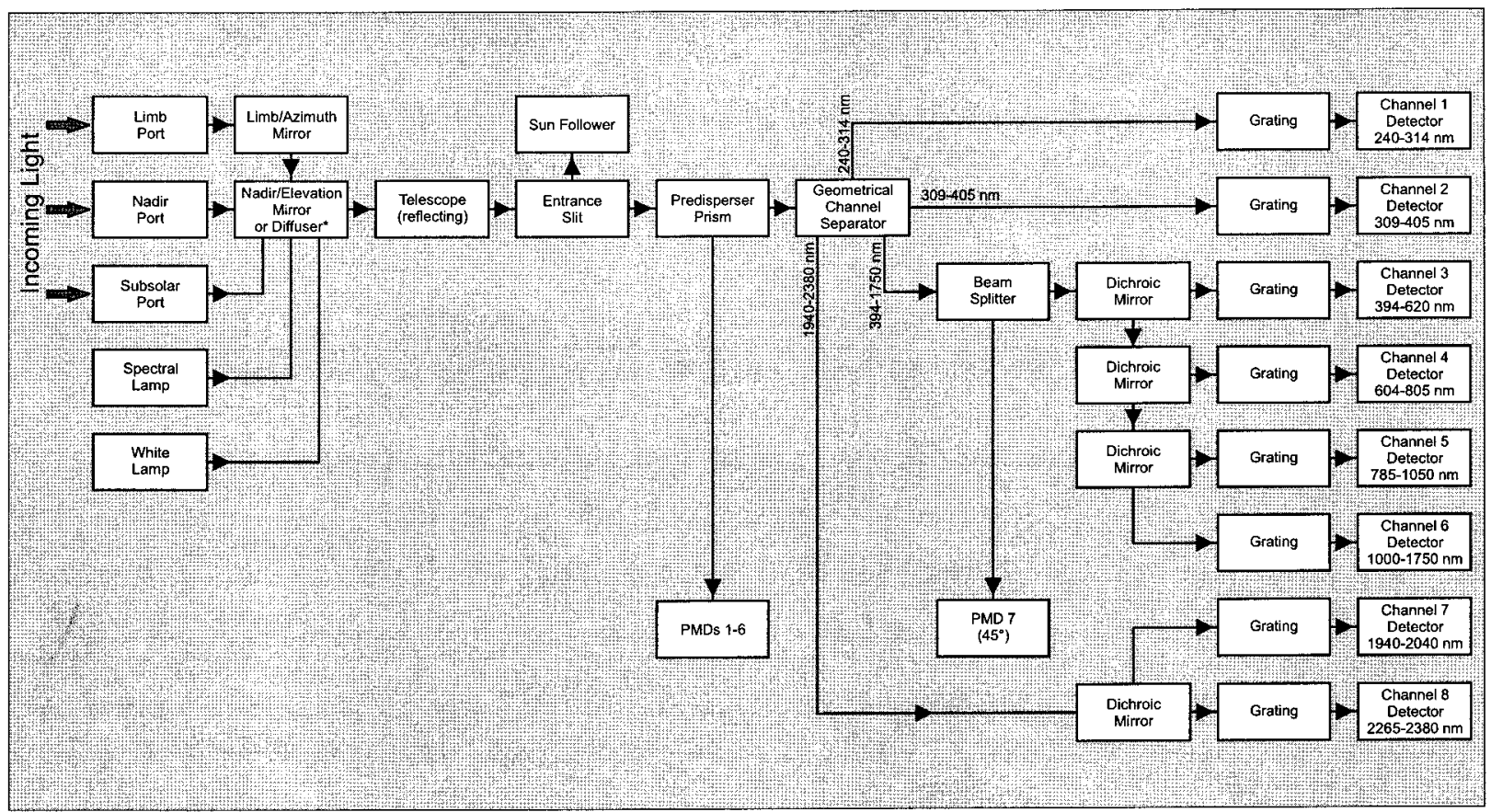

FIG. 3. Schematic view of the SCIAMACHY optical layout. All imaging optical components (mirrors, redirecting prisms, lenses, etc.) are omitted. All used gratings are in a fixed position. Each detector contains a 1024-pixel photo diode array.

fixed and the spectra are recorded simultaneously from 240 to $1750 \mathrm{~nm}$ and in two smaller windows, 1940$2040 \mathrm{~nm}$ and $2265-2380 \mathrm{~nm}$, in the near-infrared. The solar radiance varies by a factor of about 100 between 240 and $400 \mathrm{~nm}$. In comparison, the earthshine radiance varies approximately four orders of magnitude over the same spectral range. Spectrometers that measure these quantities therefore need to suppress well any stray light within the instrument. The SCIAMACHY spectrometer achieves this by the combination of a predispersing prism and gratings. This is equivalent in principle to a double spectrometer design. Initially light from the spectrometer slit is collimated and directed onto the predispersing prism. The main beam of light leaving the predispersing prism forms a spectrum in the middle of the instrument. Reflective optics are used to separate the spectrum into four parts. The shorter wavelengths of the spectrum are directed to channel $1(240-314 \mathrm{~nm})$ and channel $2(314-405 \mathrm{~nm})$ respectively. The majority of the light in the spectrum $(405-1750 \mathrm{~nm})$ passes without reflection to channels $3-6$. The infrared part of the spectrum $(1940-2380 \mathrm{~nm})$ is reflected toward channels 7 and 8 . Dichroic mirrors are used to select the wavelength ranges for channels $3,4,5$, and 6 , and to separate light for channel 7 from that for channel 8. Each individual channel comprises a grating, transmission optics, and a diode array detector. The grating further disperses the light, which is then focused onto eight linear 1024 pixel detector arrays. To minimize detector noise and dark current, the diode arrays are cooled: the detector for channels 1 and 2 to $200 \mathrm{~K}$, those for channels 3-5 to 235, that for channel 6 to $200 \mathrm{~K}$, and those for channels 7 and 8 to $150 \mathrm{~K}$. The entire instrument is cooled to $253 \mathrm{~K}$ in order to minimize the infrared emission from the instrument that might influence the detectors of channels $6-8$. In channels $1-5$ the detectors are silicon monolithic diode arrays (EG\&G Reticon RL 1024 SR). For the NIR channels 6 to 8 InGaAs detectors were developed by Epitaxx, Inc. (Joshi et al. 1992), and space qualified specifically for SCIAMACHY (see, e.g., Goede et al. 1993; van der A et al. 1997).

The spectral and radiometric characteristics of the SCIAMACHY spectrometer are summarized in Table 1. The spectral resolution of the spectrometer varies between 0.24 and $1.48 \mathrm{~nm}$ depending on channel number (see Table 1). For DOAS retrieval (see section 4) a high spectral stability is required. The instrument is designed to have a spectral stability of $1 / 50$ of a detector pixel, which requires a temperature stability of the spectrometer of better than $250 \mathrm{mK}$ over one orbit in combination with dedicated calibration measurements. The second relevant retrieval strategy (see section 4), the Full Retrieval Method (FURM) based on optimal estimation (Rodgers 1976), requires in addition to high spectral stability a high radiometric accuracy of the SCIAMACHY measurements. Knowledge of the state of polarization of the incoming light and the polarization response of the instrument determines the radiometric accuracy of the radiance, irradiance, and higher-level data products. To achieve the required radiometric accuracy 
TABLE 1. Optical parameters of the spectrometer from the design analysis

\begin{tabular}{llccc}
\hline \hline & Channel & $\begin{array}{c}\text { Spectral } \\
\text { range }(\mathrm{nm})\end{array}$ & $\begin{array}{c}\text { Resol- } \\
\text { ution } \\
(\mathrm{nm})\end{array}$ & $\begin{array}{c}\text { Stability } \\
(\mathrm{nm})\end{array}$ \\
\hline High-resolution & 1 & $240-314$ & 0.24 & 0.003 \\
channels & 2 & $309-405$ & 0.26 & 0.003 \\
& 3 & $394-620$ & 0.44 & 0.004 \\
& 4 & $604-805$ & 0.48 & 0.005 \\
& 5 & $785-1050$ & 0.54 & 0.005 \\
& 6 & $1000-1750$ & 1.48 & 0.015 \\
& 7 & $1940-2040$ & 0.22 & 0.003 \\
Polarization & 8 & $2265-2380$ & 0.26 & 0.003 \\
measurement & PMD1 & $310-377$ & broadband \\
devices & PMD2 & $450-525$ & broadband \\
& PMD3 & $617-705$ & broadband \\
& PMD4 & $805-900$ & broadband \\
& PMD5 & $1508-1645$ & broadband \\
& PMD6 & $2265-2380$ & broadband \\
& PMD7 & $802-905$ & broadband \\
Radiometric & & $2-4 \%$ & absolute \\
accuracy & & $<1 \%$ & relative \\
\hline
\end{tabular}

of $2 \%-4 \%$ (depending on the spectral region), dedicated on-ground and in-flight radiometric calibration measurements have to be performed in combination with measurements of the polarization properties of the atmosphere. For the latter purpose SCIAMACHY is equipped with seven polarization measurement devices. Six of these devices (PMD 1-6) measure light polarized perpendicular to the SCIAMACHY optical plane, generated by a Brewster angle reflection at the second face of the predispersing prism. This polarized beam is split into six different spectral bands, as described in Table 1. The spectral bands are quite broad and overlap with spectral regions of channels $2,3,4,5,6$, and 8 . The PMDs and the light path to the array detectors (including the detectors) have different polarization responses. Consequently, the appropriate combination of PMD data, array detector data, and on-ground polarization calibration data enables the polarization of the incoming light for the nadir measurements (Kruizinga et al. 1994; Frerick et al. 1997) to be determined. For atmospheric limb measurements, where both limb and nadir mirrors are used, the light is off the optical plane of the spectrometer. This requires the measurement of additional polarization information of the incoming light. A seventh PMD (PMD 7) will therefore measure the $45^{\circ} \mathrm{com}-$ ponent of the light extracted from the channels 3-6 light path, as depicted in Fig. 3. All PMDs are read out every $1 / 40 \mathrm{~s}$ and they observe the same atmospheric volume as channels $1-8$. In addition to these PMD data being used for the determination of the polarization characteristics of the incoming light, they are also planned to be used to determine the fractional cloud cover of the observed ground scene.

Additional information about the polarization of the incoming light can be obtained from the diode array overlap regions $1 / 2(309-314 \mathrm{~nm}), 2 / 3(394-405 \mathrm{~nm})$, $3 / 4(604-620 \mathrm{~nm}), 4 / 5(785-805 \mathrm{~nm})$, and 5/6 (1000$1050 \mathrm{~nm})$. The polarization efficiency is different for the measurements of the same wavelength in the different channels. Inversion of these measurements yields the ratio of plane to parallel polarization components of the incoming light in a manner similar to that used for the array and PMD detectors. The advantage of the overlap regions is that they are in small wavelength bands, having the same spectral resolution as the corresponding channel.

SCIAMACHY aims to retrieve trace gas amounts of relatively weak absorbers. For example, the differential optical density due to the $\mathrm{BrO}$ absorption around $350 \mathrm{~nm}$ detected with GOME (Burrows et al. 1999) is in the order of $10^{-3}$ and below. Therefore, to achieve a high retrieval precision, a high signalto-noise ratio $(\mathrm{S} / \mathrm{N})$ is required for the scattered radiance as well as for the solar irradiance and lunar radiance from the UV to the NIR. The predicted instrumental $\mathrm{S} / \mathrm{N}$ values as a function of wavelength are depicted in Fig. 4. These $\mathrm{S} / \mathrm{N}$ values are calculated for an individual detector pixel, for example, of nadir, limb, and occultation measurements. In most cases the predicted $\mathrm{S} / \mathrm{N}$ is well above $10^{3}$. Exceptions are found in channels 1,7 , and 8 . In channel $1 \mathrm{~S} / \mathrm{N}$ decreases toward the UV primarily because the sun is weaker and ozone absorption increases strongly from 320 to $250 \mathrm{~nm}$. In the IR channels 7 and 8 the lower $\mathrm{S} / \mathrm{N}$ values arise from the higher noise of the InGaAs detectors. For these channels the $\mathrm{S} / \mathrm{N}$ is limited by the detector noise. The apparent missing $\mathrm{S} / \mathrm{N}$ in Fig. $4 \mathrm{c}$ for channel 1 is the result of the almost complete absorption of the solar photons by the ozone layer when observing the tangent height of $15 \mathrm{~km}$. In general, higher $\mathrm{S} / \mathrm{N}$ values can be obtained by averaging measurements either temporally or spectrally at the cost of losing temporal (and consequently spatial) or spectral resolution. This strategy enables the optimal set of radiance and irradiance data to be generated for a given inversion. Summation of succeeding measurements on board (so-called onboard co-adding) is to be used to match optimally the amount of downlinked data to the ENVISAT data rate allowed for SCIAMACHY. In order to cope with the large dynamic range of the input signals (limb scattered radiance vs solar irradiance), which is of six to eight orders of magnitude, the exposure time of each channel can be selected independently over a wide range of values from 0.03125 to $80 \mathrm{~s}$. In addition, an arrangement involving an aperture stop and a neutral density filter is used to limit the intensity of the incoming light during solar occultation measurements. To optimize $\mathrm{S} / \mathrm{N}$ over the orbit, exposure times are varied as a function of the solar zenith angle.

To calibrate the instrument in flight and to monitor the instrument performance, SCIAMACHY is equipped with a $\mathrm{Pt} / \mathrm{Cr} / \mathrm{Ne}$ hollow cathode (spectral calibration), a 

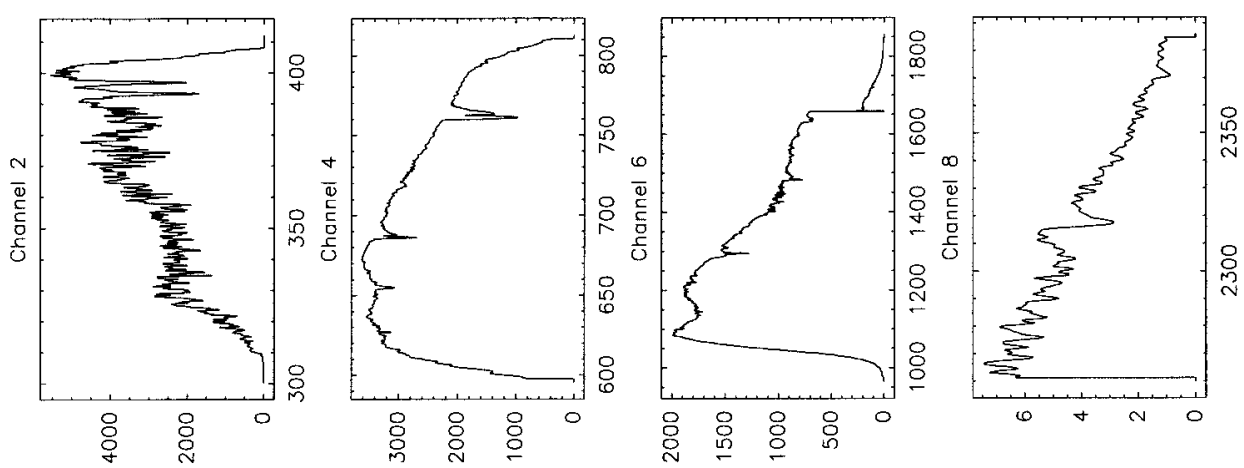

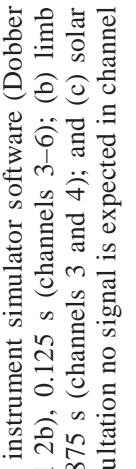
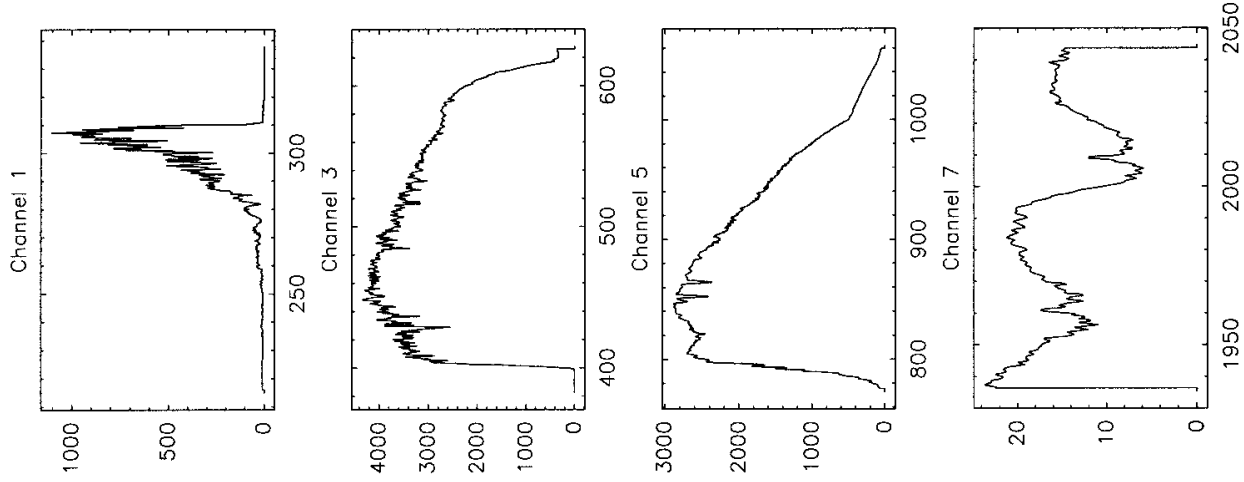

$\frac{5}{5}$

武它

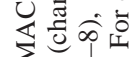

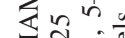

\थ

穴是

它芯

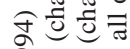

a $\sin$

สं?

๑)

苞

过可焉

อ

o!foy $\mathrm{N} / \mathrm{S}$
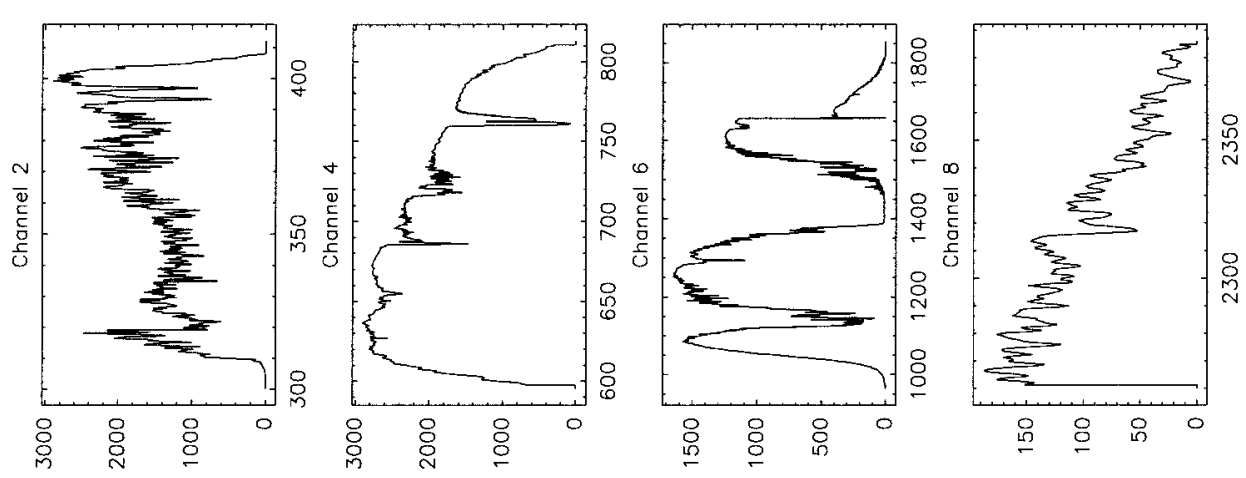

娄动

的的

oิ के

氙高造

उ

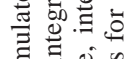

a

ไิ

远苛

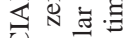

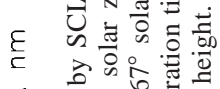

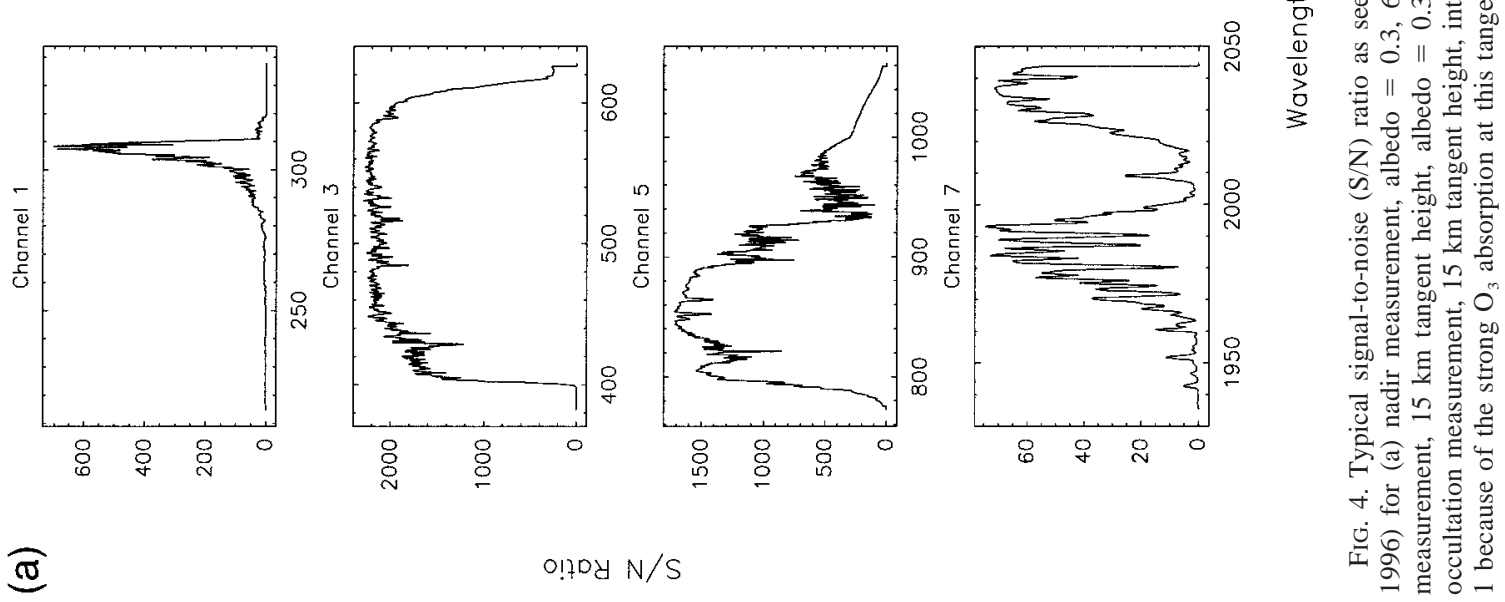


(c)
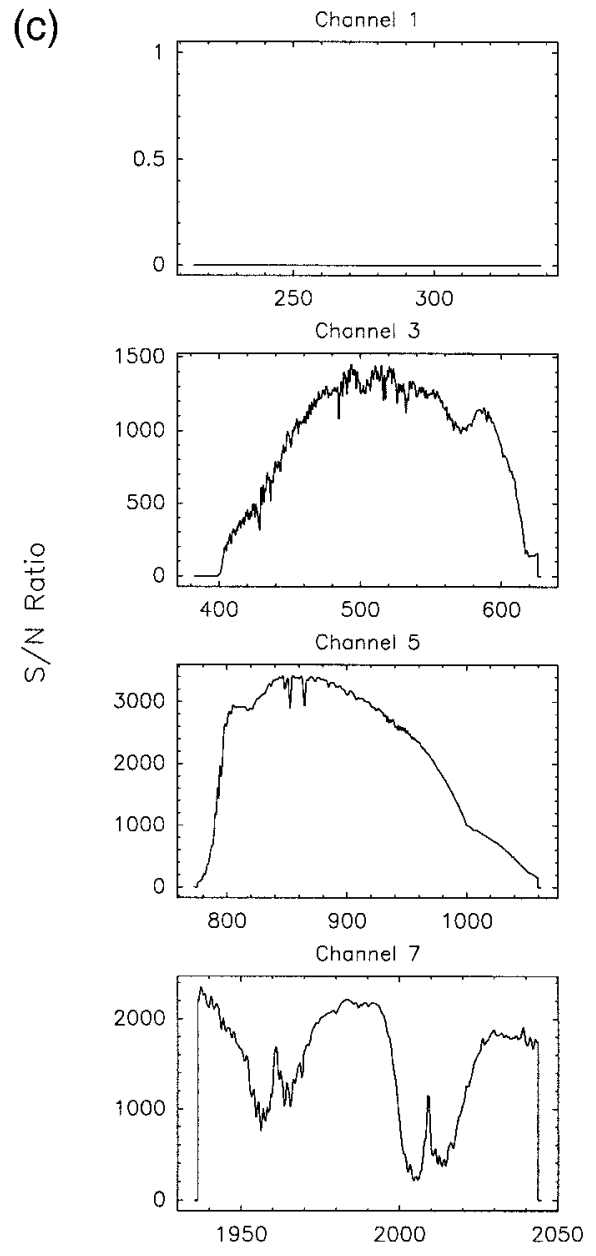

Wavelength, $\mathrm{nm}$
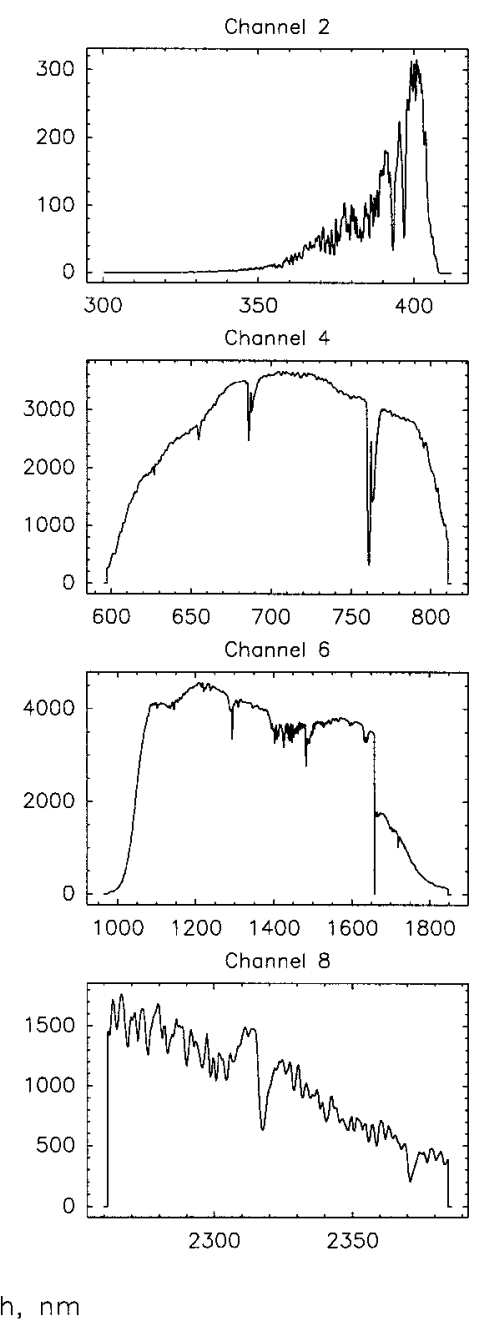

FIG. 4. (Continued) Other parameters identical for all simulations: spring season, observed atmospheric volume $55^{\circ} \mathrm{N}$, U.S. Standard Atmosphere (Anderson et al. 1994), background stratospheric aerosol, no clouds. The jump in $\mathrm{S} / \mathrm{N}$ ratio around $1650 \mathrm{~nm}$ (channel 6) results from the different detector material used below and above $1650 \mathrm{~nm}$.
5-W UV-optimized tungsten-halogen lamp with an equivalent blackbody temperature of approximately $3000 \mathrm{~K}$ (relative radiometric calibration), an extra reference mirror (monitoring of the mirror reflectivity), and a calibrated onboard diffuser (radiometric calibration via the sun).

\section{b. Observational modes, spatial coverage, and resolution}

Measurements of SCIAMACHY are performed in three different viewing geometries: nadir, limb, and solar/lunar occultation. In nadir mode the atmospheric volume beneath the spacecraft is observed. The nadir mirror scans across the satellite track and each full scan covers an area on ground of approximately 30 $\mathrm{km}$ along track by $960 \mathrm{~km}$ across track. The spatial resolution in the nadir scan mode is determined by the combination of the scan speed and the integration time of the detectors. The scan speed along track is determined by the spacecraft speed of approximately $7 \mathrm{~km} \mathrm{~s}^{-1}$. The across-track speed is determined by the nadir scan mirror rate, resulting in a scan speed of approximately $240 \mathrm{~km} \mathrm{~s}^{-1}$ on ground. The effective spatial resolution varies along the orbit for the different data products, influenced by $\mathrm{S} / \mathrm{N}$ requirements and by data rate limitations. From $60^{\circ} \mathrm{N}$ to $60^{\circ} \mathrm{S}$ the data rate is the limiting factor due to the high backscattered radiance. Onboard co-adding results in a typical spatial resolution in nadir of approximately 30 $\mathrm{km}$ along track by $240 \mathrm{~km}$ across track for all 8000 detector pixels (cf. Table 2). To minimize the loss of spatial information due to onboard co-adding, selected spectral windows, so-called clusters, can be 


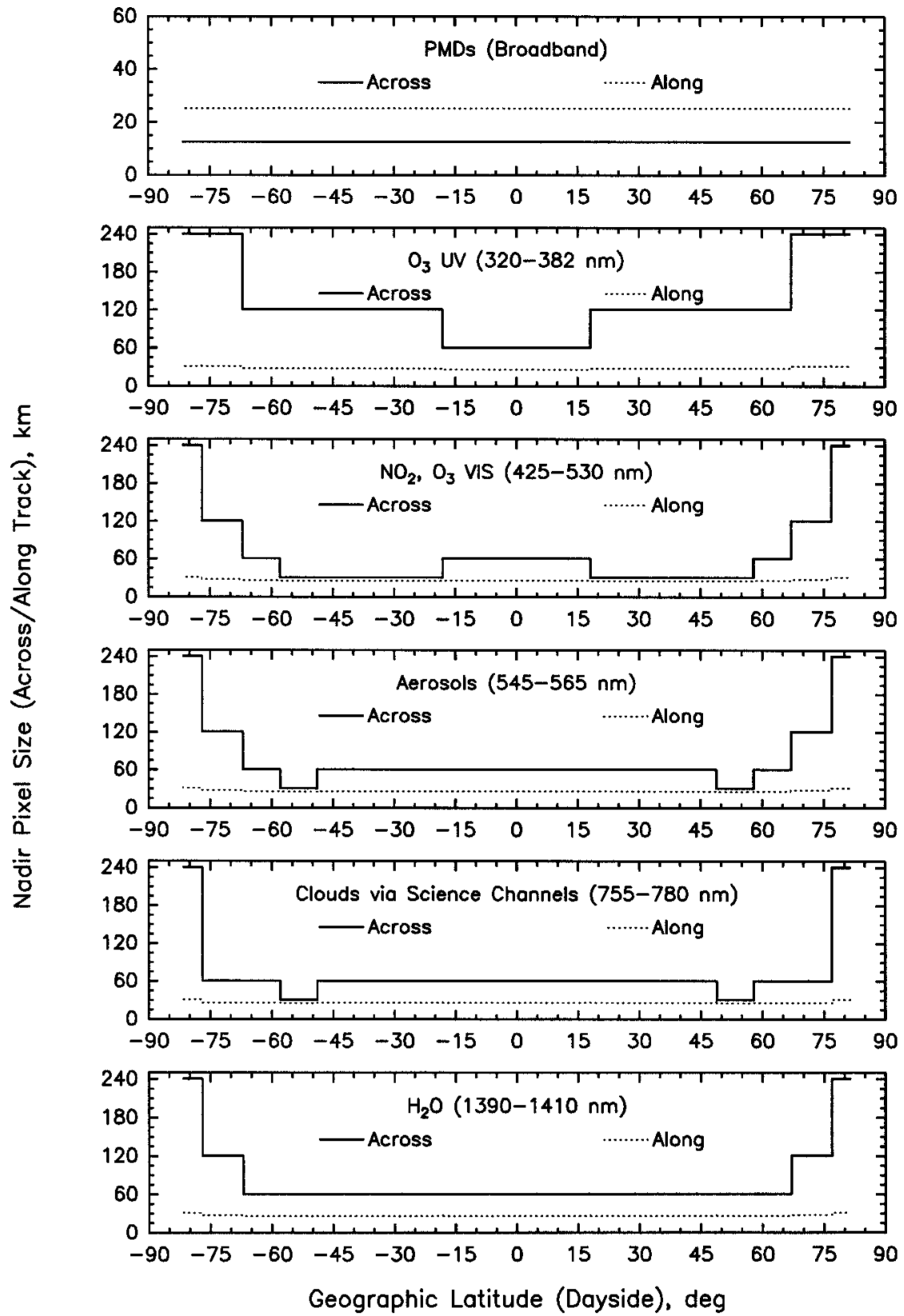

FIG. 5. Nadir pixel size across/along track for different spectral regions (clusters) as function of geographic latitude at the time of s/c equinox (spring/fall). In addition to O3, the interval from 425 to $530 \mathrm{~nm}$ also contains the spectral window for $\mathrm{NO}_{2}$ retrieval (cf. Fig. 1). Also shown is the spatial resolution of the broadband PMDs, which is independent of geographic latitude.

processed on board with reduced co-adding. This will result in a higher nadir spatial resolution for important constituents such as $\mathrm{O}_{3}, \mathrm{NO}_{2}, \mathrm{H}_{2} \mathrm{O}$, aerosols, and clouds of $30 \mathrm{~km}$ along track by $60 \mathrm{~km}$ across track, as shown in Fig. 5. The orbit dependence of the spatial resolution of selected clusters and the PMDs is shown in Fig. 5. As a consequence of their high sampling frequency, the PMDs yield measurements having the highest spatial resolution. For 50-ms effective tem- poral resolution of the PMD detectors and electronics, the PMD spatial resolution is approximately $30 \times 15$ $\mathrm{km}^{2}$ (along $\times$ across). As mentioned above, PMD data are used for polarization correction and cloud detection. The increase in the spatial resolution in the across-track direction from midlatitudes to equatorial regions results from a trade-off between the spatial resolution of the non-co-added spectral regions and that for the co-added spectral regions. This is because 
TABLE 2. Spatial coverage and resolution of SCIAMACHY measurement modes. In solar occultation mode the spatial resolution in azimuth direction is defined by the diameter of the sun.

\begin{tabular}{|c|c|c|c|c|c|}
\hline & & \multirow[b]{2}{*}{$\begin{array}{l}\text { Geometrical } \\
\text { FOV }\end{array}$} & \multirow[b]{2}{*}{ Coverage } & \multicolumn{2}{|c|}{ Typ. spatial resolution } \\
\hline & & & & $\begin{array}{l}\text { Detector } \\
\text { arrays }\end{array}$ & PMDs \\
\hline Nadir & $\begin{array}{l}\text { Along track } \\
\text { Across track }\end{array}$ & $\begin{array}{l}25 \mathrm{~km} \\
0.6 \mathrm{~km}\end{array}$ & $\begin{array}{l}\text { Continuous } \\
\pm 480 \mathrm{~km}\end{array}$ & $\begin{array}{l}30 \mathrm{~km} \\
240(60 * *) \mathrm{km}\end{array}$ & $\begin{array}{l}\approx 30 \mathrm{~km} \\
\approx 15 \mathrm{~km}\end{array}$ \\
\hline Limb & $\begin{array}{l}\text { Azimuth } \\
\text { Elevation }\end{array}$ & $\begin{array}{l}110 \mathrm{~km}^{*} \\
2.5 \mathrm{~km}^{*}\end{array}$ & $\begin{array}{l} \pm 480 \mathrm{~km}^{*} \\
0-150 \mathrm{~km} *\end{array}$ & $\begin{array}{r}240 \mathrm{~km}^{*} \\
3 \mathrm{~km} *\end{array}$ & $\begin{array}{r}\approx 30 \mathrm{~km}^{*} \\
3 \mathrm{~km}^{*}\end{array}$ \\
\hline Solar occultation & $\begin{array}{l}\text { Azimuth } \\
\text { Elevation }\end{array}$ & $\begin{array}{l}40 \mathrm{~km}^{*} \\
2.5 \mathrm{~km}^{*}\end{array}$ & $\begin{array}{l}\text { N.A. } \\
0-150 \mathrm{~km} *\end{array}$ & $\begin{array}{l}30 \mathrm{~km}^{*} \\
2.5 \mathrm{~km}^{*}\end{array}$ & $\begin{array}{r}\approx 30 \mathrm{~km}^{*} \\
2.5 \mathrm{~km}^{*}\end{array}$ \\
\hline
\end{tabular}

* At tangent point

** Selected spatial windows.

the high earthshine radiance in the equatorial regions allows the use of rather short exposure times for a given $\mathrm{S} / \mathrm{N}$ value, thus generating more data than originally foreseen for SCIAMACHY by ENVISAT.

In limb mode the spectrometer slit is projected parallel to the horizon in-flight direction by the combination of the limb and the nadir mirror. The instrument observes the atmosphere tangentially to the earth's surface taking into account effects such as the curvature of the earth's surface. In this measurement mode the limb mirror scans the atmosphere in horizontal (azimuth) direction, whereas appropriate movement of the nadir mirror results in a vertical (elevation) scan direction. A typical limb scan cycle comprises 34 horizontal scans (azimuth) at different tangent heights (elevation), starting $3 \mathrm{~km}$ below the horizon. After each horizontal scan, which has a duration of $1.5 \mathrm{~s}$, a step of $3 \mathrm{~km}$ in elevation is made by the elevation mirror. No measurements are to be made during this repositioning, which takes approximately $150 \mathrm{~ms}$. Each horizontal scan of the atmosphere in limb covers $960 \mathrm{~km}$ in the horizontal (across-track direction). The vertical resolution is approximately 3 $\mathrm{km}$. The latter is determined by the geometrical field of view (FOV), the pointing stability of the instrument and the stability of the satellite, and the multiple scattering of light in the atmosphere, which is dependent on the tangent height. The individual spatial resolution within a $960-\mathrm{km}$ scan in the horizontal direction across track is typically $240 \mathrm{~km}$, being determined by the integration time. The $960-\mathrm{km}$ total swath and the $240-\mathrm{km}$ scenes in limb viewing match explicitly the total swath and individual scenes observed in nadir. For limb observation the optical light path through the atmosphere limits the resolution in horizontal direction along track to approximately $400 \mathrm{~km}$. Due to the spacecraft velocity the atmospheric volumes observed during successive horizontal scans are slightly displaced. Within one limb cycle with a typical duration of $60 \mathrm{~s}$ the spacecraft moves roughly $400 \mathrm{~km}$ in the along-track direction. This displacement has to be taken into account by the inversion algorithm.

The ability of the SCIAMACHY instrument to ob- serve the same atmospheric volume first in limb and thereafter in nadir viewing geometries within about 7 min is perhaps one of its most important and novel features. This requires the synchronization of integration times, scan ranges, and viewing directions for all limb and nadir measurements. For the dedicated limb-nadir scanning strategy and a total swath width of $960-\mathrm{km}$ global coverage at the equator is achieved after 6 days.

Occultation measurements are performed using the elevation and azimuth scan mirrors in a manner similar to that for the limb mode, but with the sun or moon in the instrument's field of view. The instrument tracks the sun or the moon actively, resulting in a better pointing performance of the instrument. Solar occultation measurements are planned to be performed for each orbit during sunrise. For the ENVISAT orbit (cf. Table 3), solar occultation is restricted to latitudes between $65^{\circ}$ and $90^{\circ} \mathrm{N}$. Lunar occultation will be performed from half moon to full moon. For periods of 5-8 days per month lunar occultation measurements will provide latitudinal coverage from $30^{\circ}$ to $90^{\circ} \mathrm{S}$. The solar scanning strategy is similar to the SAGE II scanning (Mauldin et al. 1985): during sunrise SCIAMACHY scans several times over the full solar disc. When the sun is above the atmosphere several calibration measurements can be performed. However, for the lunar measurements longer integration times are necessary and a "stare" mode similar to that used on the Halogen Occultation Experiment (HALOE) (Russell et al. 1993) is implemented.

A typical orbit starts with a limb measurement of the twilit atmosphere, followed by the solar occultation measurement during sunrise over the North Pole and an optimized limb-nadir sequence. If the moon is visible in the Southern Hemisphere $\left(30^{\circ}-90^{\circ} \mathrm{S}\right)$, lunar occultation measurements every second orbit are performed. Note that all these measurements, with the exception of lunar occultation, are done every orbit, that is, 14 orbits per day.

In addition to the aforementioned measurements a number of calibration measurements will be performed on a regular basis (Frerick et al. 1997). These include 
TABLE 3. Summary of technical instrument data and parameters of the ENVISAT sun-synchronous polar orbit.

\begin{tabular}{|c|c|}
\hline \multicolumn{2}{|l|}{ Instantaneous field of view (IFOV) } \\
\hline Nominal IFOV & $0.045 \mathrm{deg} \times 1.8 \mathrm{deg}$ \\
\hline IFOV during solar measurements & $0.045 \mathrm{deg} \times 0.72 \mathrm{deg}$ \\
\hline \multicolumn{2}{|l|}{ Thermal control } \\
\hline $\begin{array}{l}\text { Optical bench nominal temperature } \\
\text { (orbital variation) }\end{array}$ & $253 \mathrm{~K}(0.25 \mathrm{~K})$ \\
\hline $\begin{array}{l}\text { Detector array temperature } \\
\text { (orbital variation) }\end{array}$ & $150-235 \mathrm{~K}(0.02-1.0 \mathrm{~K})$ \\
\hline \multicolumn{2}{|l|}{ In-flight calibration hardware } \\
\hline Onboard diffuser & $\begin{array}{l}\text { aluminium reflection diffus- } \\
\text { er, extra mirror }\end{array}$ \\
\hline Spectral line source & $\begin{array}{l}\text { hollow cathode discharge } \\
\text { lamp, } \mathrm{Pt} / \mathrm{Cr} \text { cathode with } \mathrm{Ne} \\
\text { filling }\end{array}$ \\
\hline White light source & $\begin{array}{l}\text { tungsten-halogen 5-W lamp } \\
\text { with equivalent blackbody } \\
\text { temperature of } 3000 \mathrm{~K}\end{array}$ \\
\hline \multicolumn{2}{|l|}{ Measurement data } \\
\hline Data processing & on board co-adding mode \\
\hline Data rate nominal (high) & $\begin{array}{l}400000 \text { bit s }^{-1}(1867000 \\
\left.\text { bit } \mathrm{s}^{-1}\right)\end{array}$ \\
\hline Datation accuracy absolute (relative) & $10 \mathrm{~ms}(1 \mathrm{~ms})$ \\
\hline ENVISAT orbit & $\begin{array}{l}\text { - sun-syncronous (1000 lo- } \\
\text { cal equator crossing time) } \\
\text { - near polar }\left(98.55^{\circ} \text { incli- }\right. \\
\text { nation) } \\
\text { - } 100.59 \text {-min orbit period } \\
\text { - } 799.8 \text {-km mean altitude } \\
\text { - } 35 \text { days repeat cycle }\end{array}$ \\
\hline
\end{tabular}

1) solar irradiance measurements,

2) spectral calibration,

3) relative radiometric calibration, and

4) dark current measurements.

Directly after solar occultation the solar irradiance above the atmosphere will be used for radiometric calibration of the instrument. A spectral calibration is to be performed with the onboard spectral light source. Relative radiometric calibration is to be achieved by the observation of the onboard white light source. During the eclipse part of the orbit dark current measurements and calibration measurements with the onboard light sources will be undertaken on a regular basis. In addition, to guarantee the optical performance and to detect long-term changes in the instrument throughput arising from degradation, special calibration orbits are defined. These will yield at least once per month the measurement of the orbital variation of the spectral and radiometric calibration. The degradation of the limb and nadir mirrors is to be monitored by using the onboard diffuser and extra mirror measurements. This enables the throughput of the spectrometer optics to be monitored over the mission lifetime (Frerick et al. 1997). The level 0 to 1 processing incorporates these calibration measurements to provide a dynamic update of the spectral and radiometric calibration.

\section{Measurement principle and retrieval methods}

In order to determine the amounts of trace constituents from SCIAMACHY's measurements a number of different retrieval techniques are to be applied. For trace gas retrieval two basic approaches are recommended.

\section{a. DOAS}

SCIAMACHY uses the retrieval technique known as Differential Optical Absorption Spectroscopy. The basic idea behind the use of DOAS to detect atmospheric constituents can be traced back to Brewer et al. (1973), who determined $\mathrm{NO}_{2}$ concentrations from the measurements of zenith sky scattered light and transmitted solar light. Platt and Perner (1980) used DOAS for long path measurements of tropospheric gases. The method has been further improved for zenith sky absorption measurements of tropospheric and stratospheric constituents from the ground (Solomon et al. 1987; Richter et al. 1998). Recently the application of DOAS to the retrieval of trace gases from spaceborne spectral measurements has been successfully demonstrated for the first time by GOME for $\mathrm{O}_{3}, \mathrm{NO}_{2}, \mathrm{BrO}, \mathrm{OClO}, \mathrm{SO}_{2}$, and $\mathrm{H}_{2} \mathrm{CO}$ (Burrows et al. 1999 and references therein). In the following the basic idea of DOAS for spaceborne spectral measurements will be described and in the appendix a derivation of the DOAS equation for two simple cases is presented. A detailed overview about the algorithm is out of the scope of this paper. An example of an operational implementation of the satellite DOAS method is given in Burrows et al. (1999).

On its way through the atmosphere the solar irradiance $F(\lambda)$ is modulated by absorption and scattering processes of molecules and particles. Given the measured earthshine radiance $I(\lambda)$ and the solar irradiance $F(\lambda)$, both measured by SCIAMACHY, and the absorption cross sections $\sigma_{i}(\lambda)$ of all relevant species, their slant column densities $\mathrm{SCD}_{i}$ are fitted together with polynomial coefficients $c_{j}$ according to Lambert-Beer's law for the slant optical density:

$$
\tau_{s}(\lambda)=-\ln \left(\frac{I(\lambda)}{F(\lambda)}\right) \approx \sum_{i} \sigma_{i}(\lambda) \operatorname{SCD}_{i}(\lambda)-\sum_{j} c_{j} \lambda^{j} .
$$

While molecular absorption cross sections $\sigma_{i}(\lambda)$ are usually highly structured, absorption by particles, scattering by molecules and particles, and also reflection at the surface are broadband features. All these broadband modulations of the solar irradiance are described in the DOAS approach by a common polynomial of low order. The slant column density $\mathrm{SCD}_{i}$ is the particle number density $n_{i}$ integrated along the light path $s$, which may depend on the wavelength of the scattered light:

$$
\operatorname{SCD}_{i}(\lambda)=\int n_{i}(s) d s(\lambda) .
$$


One complication that must be taken into account is inelastic scattering, which produces a filling in of the Fraunhofer structures of the backscattered solar spectrum. This effect is known as the Ring effect after its discoverer (Grainger and Ring 1962). Filling in is caused predominantly by rotational Raman scattering in the atmosphere. The Ring effect will be taken into account in the fitting procedure as an additional "absorber" with an effective cross section $\sigma_{\text {Ring }}(\lambda)$, as proposed originally by Solomon et al. (1987).

The spectral fit window will be selected in such a way that the $\operatorname{SCD}_{i}$ can be assumed to be independent of wavelength. Then the $\mathrm{SCD}_{i}$ will be obtained by a linear least squares fit of

$$
\left\|\tau_{s}(\lambda)-\sum_{i} \sigma_{i}(\lambda) \mathrm{SCD}_{i}+\sum_{j} c_{j} \lambda^{j}\right\|^{2} .
$$

Fit parameters are the slant column densities $\mathrm{SCD}_{i}$ and the polynomial coefficients $c_{j}$.

Once the $\mathrm{SCD}_{i}$ have been determined the conversion to the desired vertical column densities $\mathrm{VCD}_{i}$ is the next step. This requires for each trace gas a division by a suitable airmass factor $\left(\mathrm{AMF}_{i}\right)$ :

$$
\mathrm{VCD}_{i}=\int n_{i}(z) d z=\mathrm{SCD}_{i} / \mathrm{AMF}_{i} .
$$

Here $n_{i}(z)$ is the vertical number density profile of the $i$ th absorber. The AMF describes the enhancement of the absorption due to the slant path viewing geometry and the solar elevation. It depends on the measurement geometry and on the vertical profiles of absorbing and scattering constituents in the atmosphere. The AMF can be calculated with a radiative transfer model (RTM) and is essentially the ratio of a simulated atmospheric radiance including all trace gases and a second simulated radiance with the trace gas of interest excluded in the calculation (Sarkissian et al. 1995; Burrows et al. 1999). The RTM SCIATRAN, which is an extension of the radiation transfer model GOMETRAN (Rozanov et al. 1997; Rozanov et al. 1998) might be used for this purpose. The RTM calculation requires trace gas profiles as input, which will be taken from trace gas climatologies. Partial or complete cloud cover can be accounted for in the VCD calculation (Burrows et al. 1999).

In current implementations of the DOAS algorithm, the wavelength dependence of the AMF is neglected. For a typical fitting window the AMF is calculated for only one representative wavelength, which results in additional errors in the calculated VCD. The height dependence of the absorption cross section due to temperature dependence is an additional error source (Burrows et al. 1999). These error sources can be minimized by using the so-called modified DOAS approach, where the fit parameter $k_{i}$ is a scaling factor for the modeled slant optical density, $\operatorname{SOD}_{i}^{\text {mod }}$ (Burrows et al. 1999, their appendix C). For modified DOAS the measured total slant optical density $\tau_{s}$ will be approximated by

$$
\tau_{s}(\lambda) \approx \sum_{i} k_{i} \operatorname{SOD}_{i}^{\bmod }(\lambda, s)-\sum_{j} c_{j} \lambda^{j},
$$

with

$$
\operatorname{SOD}_{i}(\lambda)=\int_{s} \sigma_{a i}(s, \lambda) n_{a i}(s) d s,
$$

where $k_{i}$ is the ratio of the $\mathrm{VCD}_{i}$ to be retrieved to the $\mathrm{VCD}_{i}^{\text {mod }}$ used for the model calculation of $\mathrm{SOD}_{i}^{\mathrm{mod}}$. In appendix $\mathrm{C}$ of Burrows et al. it was shown that for an atmosphere with only one absorber that $\mathrm{SOD}_{i}^{\bmod }$ can be calculated as the ratio of simulated atmospheric radiance including all trace gases and a second simulation with the trace gas of interest excluded in the calculation. In the appendix it is demonstrated that for single scattering and multiple absorbers $\mathrm{SOD}_{i}^{\text {mod }}$ can be calculated in the same way, assuming an optically thin atmosphere. This results in the modified DOAS equation for multiple absorbers:

$$
\tau_{s}(\lambda) \approx \sum_{i} \frac{\mathrm{VCD}_{i}}{\operatorname{VCD}_{i}^{\bmod }} \cdot \ln \left(\frac{I_{-i}^{\bmod }(\lambda)}{I^{\bmod }(\lambda)}\right)-\sum_{j} c_{j} \lambda^{j},
$$

where $I_{-i}^{\bmod }(\lambda)$ is the calculated radiance without the $i$ th absorber and $I^{\bmod }(\lambda)$ is the calculated radiance with all absorbers. As pointed out in appendix $\mathrm{C}$ of Burrows et al. (1999), the modified DOAS equation (7) allows an iterative solution to compensate for a possible dependence of $\mathrm{VCD}_{i}$ on $\mathrm{VCD}_{i}^{\text {mod }}$.

Then $\mathrm{VCD}_{i}$ will be obtained directly by a linear least squares fit of

$$
\left\|\tau_{s}(\lambda)-\sum_{i} \frac{\mathrm{VCD}_{i}}{\mathrm{VCD}_{i}^{\text {mod }}} \cdot \ln \left(\frac{I_{-i}^{\bmod }(\lambda)}{I^{\bmod }(\lambda)}\right)+\sum_{j} c_{j} \lambda^{j}\right\|^{2} .
$$

Fit parameters are the vertical column densities $\mathrm{VCD}_{i}$ and the polynomial coefficients $c_{j}$.

Modified DOAS was first used for the interpretation of ground-based zenith sky observations (Richter et al. 1998). An application of modified DOAS to $\mathrm{O}_{3}$ retrieval from GOME satellite data is presented in Burrows et al. (1999). In the appendix some more details about the physical basics are presented in the form of two instructive examples for the nadir geometry for multiple absorbers: (i) light scattered at the earth's surface only and (ii) light singly scattered in the atmosphere.

\section{b. FURM full retrieval method}

The FURM algorithm consists of two parts: (i) a forward model and (ii) an inversion scheme. SCIATRAN, a significant extension of the radiation transfer model GOMETRAN (Rozanov et al. 1997; Rozanov et al. 1998), will be used as the forward RTM to calculate for the relevant geometry the radiance for a given state of the atmosphere. The optimal estimation scheme 
(Rodgers 1976) is used to invert the data. It matches in iterative steps the calculated radiance to the measured radiance by modifying model atmospheric parameters such as the vertical distribution of $\mathrm{O}_{3}$ using appropriate weighting functions provided by the radiative transfer model (Rozanov et al. 1998). The successful retrieval of $\mathrm{O}_{3}$ profile information with FURM from GOME nadir measurements has already been demonstrated (De Beek et al. 1997; Munro et al. 1998). Details about FURM are presented in Burrows et al. (1999). Currently, limb and occultation retrieval algorithms, based on the forward model SCIATRAN and an inversion approach, are being developed at the University of Bremen.

\section{c. Retrieval of tropospheric column information}

For the inversion from radiance and irradiance to tropospheric column information two methods are to be used.

\section{1) The Residual APPROACH}

For this method the difference between a total column determined from nadir observations and a stratospheric column derived from limb (or occultation) measurements yields tropospheric column densities. This approach is known for tropospheric $\mathrm{O}_{3}$ retrieval as the tropospheric residual method (Fishman et al. 1990). The feasibility of this method has been investigated for tropospheric $\mathrm{O}_{3}$ by subtracting $\mathrm{SAGE}$ stratospheric $\mathrm{O}_{3}$ columns from TOMS total $\mathrm{O}_{3}$ columns (Fishman et al. 1990) or by subtracting SBUV stratospheric $\mathrm{O}_{3}$ columns from TOMS total $\mathrm{O}_{3}$ columns (Fishman et al. 1996). In the past one of the main limitations of the method has been the inadequate spatial and temporal overlap between the measurement pair. SCIAMACHY overcomes this problem by using a dedicated limb-nadir observation strategy, described in section 3 , where subsequent limb and nadir measurements of the same air volume are made within $7 \mathrm{~min}$ of one another. Using SCIAMACHY data, the residual method is to be applied to tropospheric column retrieval of $\mathrm{O}_{3}, \mathrm{NO}_{2}, \mathrm{BrO}, \mathrm{SO}_{2}$, $\mathrm{H}_{2} \mathrm{O}, \mathrm{H}_{2} \mathrm{CO}, \mathrm{N}_{2} \mathrm{O}, \mathrm{CO}, \mathrm{CH}_{4}$, and aerosol (cf. Fig. 2).

\section{2) TROPOSPHERIC DATA FROM NADIR MEASUREMENTS}

For the special case of $\mathrm{O}_{3}$, and possibly also for $\mathrm{H}_{2} \mathrm{O}$ and aerosol, it is feasible to derive tropospheric distributions from the analysis of saturated and unsaturated atmospheric absorptions (Chance et al. 1996; Munro et al. 1998; Burrows et al. 1999 and references therein). The strong variation of the optical thickness with height and wavelength enables the retrieval of height-resolved information with a vertical resolution of 6-10 km, depending on the altitude. This approach was first proposed by Singer and Wentworth (1957) and has been successfully applied to data from SBUV instruments
(Bhartia et al. 1996) to derive vertical stratospheric $\mathrm{O}_{3}$ profiles from nadir measurements. In addition, it has been pointed out that the simultaneous observation of the $T$-dependent Huggins bands and the $T$-independent Chappuis bands provides additional information about tropospheric $\mathrm{O}_{3}$ from nadir measurements (Chance et al. 1996). Auxiliary information about temperature and pressure profiles can be determined from retrievals of the well-mixed gases $\mathrm{CO}_{2}$ and $\mathrm{O}_{2}$. Explicitly, temperature will be retrieved from the Boltzmann distribution of the vibrational-rotational structure of molecular absorption bands. Their number density will be determined from the $T$-invariant effective oscillator strength.

\section{Precision estimates of SCIAMACHY trace gas measurements}

From the inception of the SCIAMACHY project sensitivity studies have been performed by members of the original SCIAMACHY science team (Burrows et al. 1988; Chance et al. 1991) and later the Science Advisory Group and their institutes (Burrows et al. 1992; Burrows and Chance 1992; Burrows et al. 1994; Guyenne and Readings 1993; Rozanov et al. 1992; Schrijver et al. 1995). In the aforementioned studies, with the exception of Burrows et al. (1992) (see section 5a), noise and instrument performance was estimated using different variants of a SCIAMACHY instrument model. The radiation entering SCIAMACHY was simulated using a radiative transfer model coupled with a line by line model of the atmospheric absorptions where necessary. In this section estimates of the expected precision of SCIAMACHY data are summarized with respect to the current instrument performance. Table 4 provides an updated summary of the estimated precision of trace gas absorption and emission measurements in the different measurement modes, combining the results from the different sensitivity studies. The estimation of the absorption or emission precision requires the inversion of the precision with a forward radiative transfer model describing the viewing geometry. The simplest RTM is for occultation measurements. The estimated precision for the limb and occultation retrievals depends strongly on the tangent height. This is because the concentration of gases, but not necessarily their mixing ratio, usually falls off with altitude and because for the limb measurements the signal is dependent on the amount of scattered light, which depends on the pressure at a given tangent height. The retrieval precisions for occultation measurements in the UV-VIS as well as nadir retrieval precision in the NIR will be discussed in more detail below.

\section{a. Retrieval precisions for solar and lunar occultation measurements}

For SCIAMACHY occultation measurements Burrows et al. (1992) reported on the precision to be ex- 
TABLE 4. Summary of theoretical precision estimates of targeted trace gases. Note that for limb profiles the precision depends strongly on altitude. A question mark (?) indicates feasibility study necessary to determine retrieval precision.

\begin{tabular}{|c|c|c|c|c|c|}
\hline \multirow[b]{3}{*}{ Molecule } & \multirow{3}{*}{$\begin{array}{l}\text { Nadir } \\
\text { column }\end{array}$} & \multicolumn{3}{|c|}{ Vertical profiles } & \multirow{3}{*}{$\begin{array}{c}\text { Nadir-limb } \\
\text { tropos- } \\
\text { pheric } \\
\text { column }\end{array}$} \\
\hline & & \multicolumn{2}{|c|}{ Occultation } & \multirow[b]{2}{*}{ Limb } & \\
\hline & & Solar & Lunar & & \\
\hline $\mathrm{O}_{3}$ & $\approx 1 \%$ & $\approx 1 \%$ & $2 \%$ & $10 \%$ & $10 \%$ \\
\hline $\mathrm{NO}_{2}$ & $2 \%{ }^{\mathrm{e}}$ & $\approx 1 \%$ & $5 \%$ & $10 \%$ & $10 \%$ \\
\hline $\mathrm{NO}_{3}$ & $5 \%$ & $50 \%$ (day) & $\begin{array}{c}10 \% \\
\text { (twilight) }\end{array}$ & $?$ & \\
\hline $\mathrm{BrO}$ & $5 \%$ & $5 \%$ & $?$ & $50 \%$ & $?$ \\
\hline $\mathrm{OCIO}^{\mathrm{d}}$ & $5 \%$ & $2 \%$ & $5 \%$ & $?$ & - \\
\hline $\mathrm{CIO}^{\mathrm{d}}$ & $20 \%$ & $50 \%$ & $?$ & $50 \%$ & - \\
\hline $\mathrm{H}_{2} \mathrm{CO}^{\mathrm{a}, \mathrm{b}}$ & $20 \%$ & - & - & $?$ & $25 \%$ \\
\hline $\mathrm{SO}_{2}{ }^{\mathrm{a}}$ & $10 \% \mathrm{e}^{\mathrm{e}}$ & - & - & $?$ & $10 \%$ \\
\hline $\mathrm{H}_{2} \mathrm{O}$ & $1 \%$ & $\approx 1 \%$ & & $10 \%$ & $\approx 5 \%$ \\
\hline $\mathrm{N}_{2}^{2} \mathrm{O}$ & $5 \%$ & $\approx 1 \%$ & $5 \%$ & $10 \%$ & $\approx 10 \%$ \\
\hline $\mathrm{CO}$ & $5 \%$ & $1.5 \%$ & & $10 \%$ & $\approx 10 \%$ \\
\hline $\mathrm{CO}_{2}$ & $1 \%$ & $\approx 1 \%$ & & $10 \%$ & $\approx 5 \%$ \\
\hline $\mathrm{CH}_{4}$ & $1 \%$ & $\approx 1 \%$ & & $10 \%$ & $\approx 5 \%$ \\
\hline $\mathrm{NO}^{\mathrm{c}}$ & $20 \%$ & $\approx 1 \%$ & & $10 \%$ & - \\
\hline $\mathrm{O}_{4}$ & $5 \%$ & $10 \%$ & & $20 \%$ & $10 \%$ \\
\hline & $\approx 1 \%$ & $\approx 1 \%$ & & $10 \%$ & $10 \%$ \\
\hline $\mathrm{O}_{2}\left({ }^{1} \Delta_{\mathrm{g}}\right)$ & $\approx 1 \%$ & $\approx 1 \%$ & & $10 \%$ & \\
\hline
\end{tabular}

a Polluted trapospheric conditions.

${ }^{b}$ Biogenic emissions and biomass burning.

c Estimated knowledge of column above $40 \mathrm{~km}$.

${ }^{\mathrm{d}}$ Under ozone hole conditions.

e Feasibility of the retrieval of $\mathrm{SO}_{2}, \mathrm{BrO}, \mathrm{OCIO}, \mathrm{H}_{2} \mathrm{CO}$, and $\mathrm{NO}_{2}$ total column amount was already shown by GOME (Burrows et al. 1999).

pected for the "minor" trace gases $\mathrm{BrO}, \mathrm{OClO}$, and $\mathrm{NO}_{3}$ (Table 4). Here the results of the retrieval precision of $\mathrm{O}_{3}$ and $\mathrm{NO}_{2}$ from solar and lunar occultation measurements under background stratospheric aerosol condition are summarized and compared to retrieval precisions of SAGE II (Chu et al. 1989) and OZON-M (Timofeyev et al. 1986). Using a radiative transfer model for occultation, appropriate assumptions about the instrument error, and an optimal estimation retrieval scheme (Timofeyev et al. 1986) the precision of $\mathrm{O}_{3}$ and $\mathrm{NO}_{2}$ for a typical midlatitude scenario at the spring equinox was investigated. Figure 6 shows the retrieval precision for both trace gases as a function of altitude. For $\mathrm{O}_{3}$ retrieval both the Hartley-Huggins and the Chappuis spectral bands were used. The instrument noise was assumed to be constant with altitude. The total error combines instrument and shot noise. For solar occultation the combined noise to signal ratio is in the order of $10^{-4}$ (cf. $\mathrm{S} / \mathrm{N}$ in Fig. 4c) resulting in a theoretical retrieval precision on the absorption measurements of better than $0.1 \%$ between 15 and $60 \mathrm{~km}$ (cf. Fig. 6a). Below $22 \mathrm{~km}$ the retrieval precision decreases with decreasing altitude due to the presence of the stratospheric aerosol layer, which scatters light and results in fewer photons reaching the instrument. For the SCIAMACHY lunar occultation measurements significantly lower light fluxes will be detected and the combined noise to signal ratio is larger, being approximately $10^{-3}$. As a consequence the retrieval precision for absorption is less than $0.3 \%$ from 15 to $60 \mathrm{~km}$. In Table 4 typical theoretical retrieval precisions are included (cf. Fig. 6).

Figure 6 also includes a precision estimate for the instruments SAGE II and OZON-M. SAGE II uses seven spectral bands between $385 \mathrm{~nm}$ and $1.02 \mu \mathrm{m}$ (Mauldin et al. 1985). The Russian OZON-M experiment measures solar occultation by continuously scanning in four spectral intervals: $260-300 \mathrm{~nm}, 360-420 \mathrm{~nm}, 600-690$ $\mathrm{nm}$, and 910-1040 $\mathrm{nm}$ at a spectral resolutions of 0.2 , $0.3,0.5$, and $0.8 \mathrm{~nm}$, respectively. Estimated retrieval precisions were simulated by the same method as for SCIAMACHY and are shown in Fig. 6. The estimated SAGE II precision is in reasonable agreement with estimates of Chu et al. (1989), who predicted a precision of about $10 \%$ between cloud-top height and $60 \mathrm{~km}$.

The theoretical simulations indicate that the SCIAMACHY precision for ozone absorption measurements is potentially very high. There are two main reasons for this predicted high precision: (i) the simultaneous observation of Hartley-Huggins and Chappuis absorption and (ii) the intrinsically low instrumental noise of the diode array detectors.

However, in practice, the precision is expected to be limited by a variety of effects: (i) the knowledge of the molecular absorption cross sections, (ii) the pointing error, and (iii) the conversion of a slant column absorption or emission to a tangent height or pressure profile (concentration or mixing ratio).

For the $\mathrm{NO}_{2}$ retrieval precision, a behavior similar to that for $\mathrm{O}_{3}$ is obtained and is shown in Fig. 6b. In lunar occultation a retrieval precision of better than $4 \%$ between 15 and $45 \mathrm{~km}$ can be achieved, whereas for the solar occultation this precision is well below $1 \%$. The reduction in the precision above $45 \mathrm{~km}$ is mainly due to the lower abundance of $\mathrm{NO}_{2}$ in this region. In comparison to SAGE II and OZON-M, the precision of $\mathrm{NO}_{2}$ from SCIAMACHY is predicted to be about a factor of more than 4 better.

It is interesting to point out here that molecular scattering can also be determined from SCIAMACHY's occultation measurements with a high precision and yields estimates of the molecular number density, which can directly be inverted to yield pressure profiles.

\section{b. Nadir $\mathrm{CO}, \mathrm{CH}_{4}, \mathrm{H}_{2} \mathrm{O}, \mathrm{N}_{2} \mathrm{O}$ precisions}

One important goal of SCIAMACHY is to retrieve $\mathrm{CO}$ and $\mathrm{CH}_{4}$ (beside other absorbers like $\mathrm{O}_{3}, \mathrm{NO}_{2}, \mathrm{H}_{2} \mathrm{O}$, $\mathrm{N}_{2} \mathrm{O}$, and $\mathrm{CO}_{2}$ ) down to the ground or cloud top. The retrieval precisions of $\mathrm{CO}, \mathrm{CH}_{4}, \mathrm{~N}_{2} \mathrm{O}$, and $\mathrm{H}_{2} \mathrm{O}$ in the NIR channel $8(2265-2380 \mathrm{~nm})$ from nadir measurements are discussed below. This report updates, using the current instrument and detector performance, the findings of previous studies (Schrijver et al. 1995). For this study the radiance reaching the SCIAMACHY en- 
PRECISION OF RETRIEVAL OF OZONE

(a) (Condition: Background Stratospheric Aerosol)

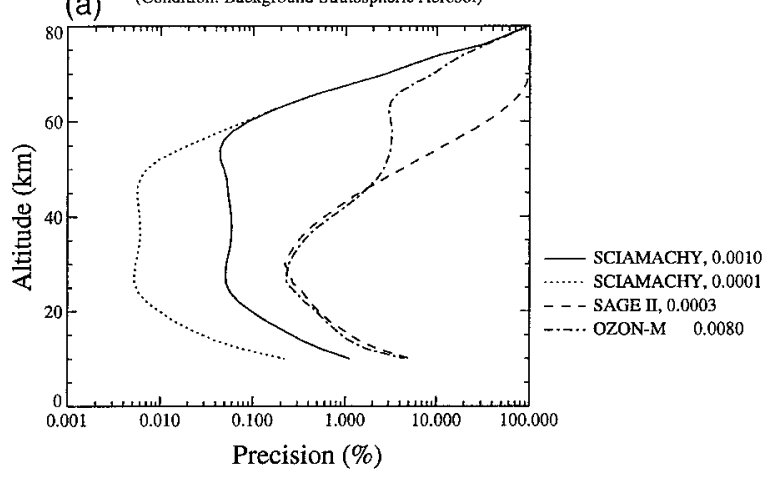

PRECISION OF RETRIEVAL OF NITROGEN DIOXIDE

(b) (Condition: Background Stratospheric Aerosol)

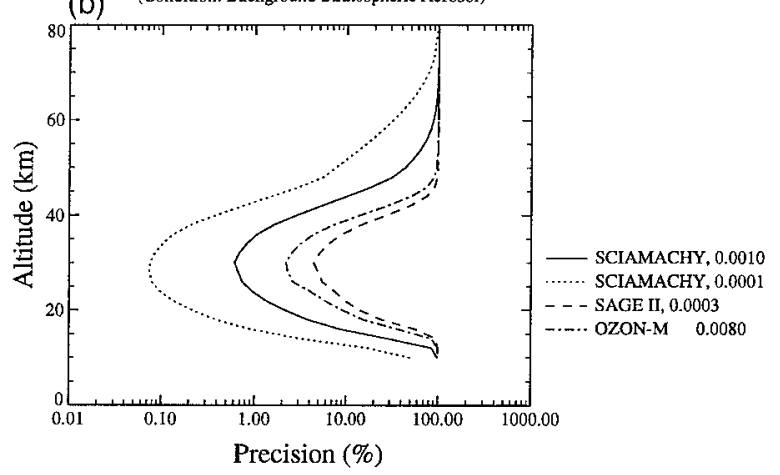

FIG. 6. Theoretical precision estimates for $\mathrm{O}_{3}$ and $\mathrm{NO}_{2}$ from occultation measurements under background stratospheric aerosol conditions and comparison with SAGE II and OZON-M. SCIAMACHY lunar occultation instrumental error: straight line; SCIAMACHY solar occultation instrumental error: dotted line; SAGE II instrumental error: dashed line; OZON-M instrumental error: dashed-dotted line. (a) $\mathrm{O}_{3}$ retrieval precision and (b) $\mathrm{NO}_{2}$ retrieval precision. All instrument errors are assumed to be independent of height. Pointing errors and errors in the absorption cross section are neglected.

trance slit was simulated by using the radiative transfer model FASCODE/MODTRAN (Clough et al. 1981). The instrument response including detector noise was calculated with the SCIAMACHY instrument simulator software (Slijkhuis 1994) for an integration time of 1 s. The computed noise was used to estimate uncertainties in the determination of concentrations of the relevant trace gases using the Cramer-Rao formalism (Kendall and Stuart 1979). The relative and absolute $1 \sigma$ precisions were calculated as a function of albedo, season, and latitude for a single SCIAMACHY observation. Figure 7 summarizes the outcome of these simulations as a function of albedo. The origin of the difference between the $50^{\circ} \mathrm{N}$ and $40^{\circ} \mathrm{S}$ scenario is the higher $\mathrm{CO}$ total column in the Northern Hemisphere (for details see Schrijver et al. 1995). The estimated retrieval precision of $\mathrm{CO}$ varies little between the different scenarios when expressed in absolute amounts: the standard deviation $\sigma$ is mostly of the order of $10^{17} \mathrm{~mol} \mathrm{~cm}{ }^{-2}$. Variations in the relative precisions of $\mathrm{CO}$ are determined predominately by the variation of the $\mathrm{CO}$ concentrations around the globe. For the Northern Hemisphere the retrieval precision of $\mathrm{CO}$ varies in the range 3\%-10\%, whereas for the Southern Hemisphere for a clean remote troposphere it can be higher than $20 \%$. For $\mathrm{CH}_{4}$, studies yield minimum detectable columns of the order of $5 \times$ $10^{16} \mathrm{~mol} \mathrm{~cm}^{-2}$ resulting in a precision of the order of $1 \%$ for a single measurement. Variations with latitude are much less pronounced for $\mathrm{CH}_{4}$ because of the smoother variation of the model column with latitude.

In addition, Schrijver et al. (1995) studied the retrieval precision of $\mathrm{N}_{2} \mathrm{O}$ and $\mathrm{H}_{2} \mathrm{O}$. $\mathrm{N}_{2} \mathrm{O}$ can be measured with a precision of 3\%-10\%, nearly independent of latitude, and the $\mathrm{H}_{2} \mathrm{O}$ precision lies well below the $1 \%$ limit. As previously reported by Ashcroft and Morel (1995), there is a strong correlation between $\mathrm{H}_{2} \mathrm{O}$ and $\mathrm{CH}_{4}$ in the 2.3- $\mu \mathrm{m}$ wavelength region, which may make it necessary to retrieve $\mathrm{H}_{2} \mathrm{O}$ from an independent spectral window where no $\mathrm{CH}_{4}$ structures appears. Nevertheless it is expected that the retrieved amounts of $\mathrm{CH}_{4}$ from the relatively high spectral resolution of $0.26 \mathrm{~nm}$ around $2.3 \mu \mathrm{m}$ in channel 8 of SCIAMACHY measurements have insignificant interference from the $\mathrm{H}_{2} \mathrm{O}$ absorptions.

\section{Operational data products}

An operational data product is defined for SCIAMACHY and ENVISAT purposes as being a regularly generated, quality controlled, and archived data product. Currently it is foreseen that all limb and nadir measurement segments will be processed operationally within the ENVISAT ground segment. Scientific products for process studies from lunar and solar occultation measurements as well as special tropospheric products are planned to be generated for the atmospheric research and related communities by specific scientific groups.

SCIAMACHY operational data products are divided into two categories: the fast delivery (FD) products and the offline (OL) products. The FD products are to be generated directly after downlink at the ESA ground stations in near-real time, a few hours after the spectrum is acquired. The OL products comprise a set of consolidated and fully calibrated products. The latter are to be processed offline at the German Processing and Archiving Center as part of the ENVISAT ground segment.

SCIAMACHY operational data products are defined in several levels. The level 1 product results from the application of calibration parameters, orbit, and attitude information to the raw data and yields geolocated and calibrated spectral radiance and irradiance. These data comprise the extraterrestrial solar irradiance and the spectral radiance of scattered solar 
(a)

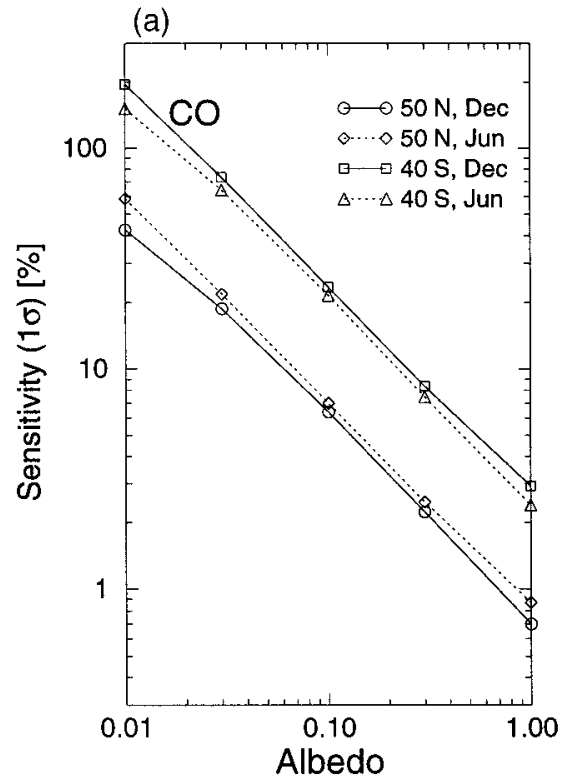

(b)

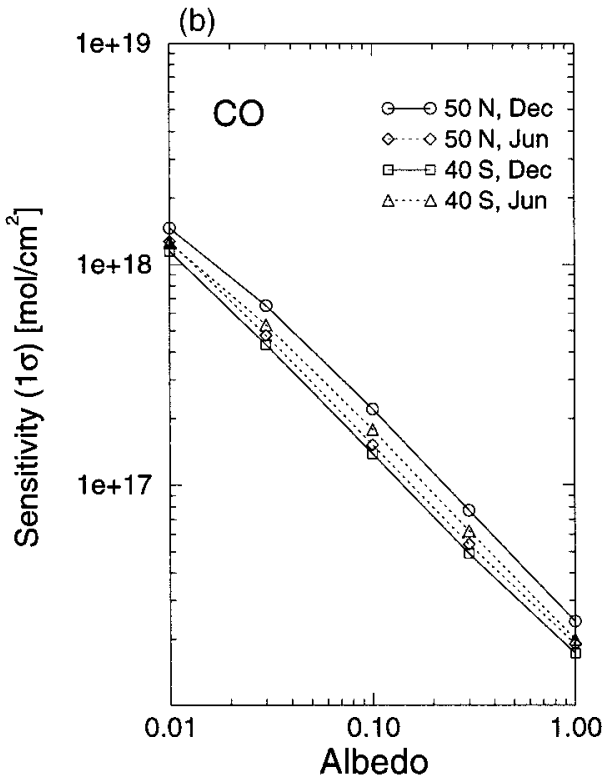

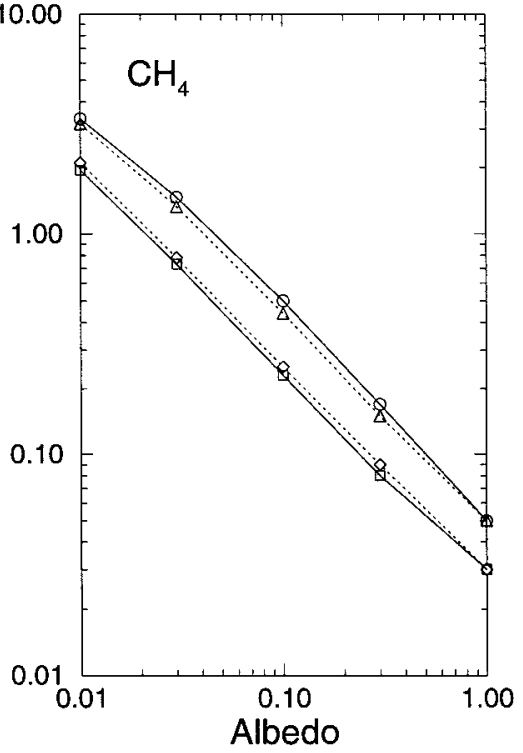

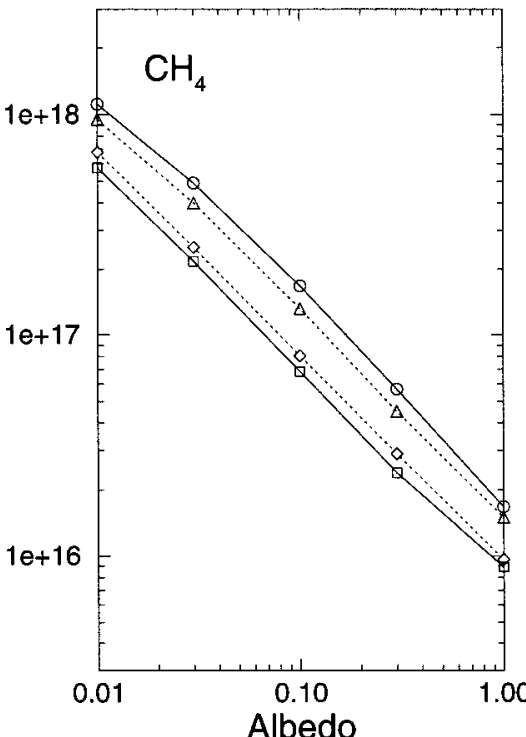

FIG. 7. Theoretical retrieval precision of tropospheric $\mathrm{CO}$ and $\mathrm{CH}_{4}$ concentrations for four combinations of month and latitude as a function of albedo for 1-s integration time in channel 8 (2265$2380 \mathrm{~nm}$ ): (a) precision in percent and (b) precision in column density $\left(\mathrm{mol} \mathrm{cm}^{-2}\right)$.

radiation modified by absorption on its path through the earth's atmosphere. From these level 1 products the profiles and column densities of various atmospheric constituents are retrieved to yield geolocated, calibrated concentrations of trace gases, as well as aerosol and cloud information (level 2 products). At present the level 2 FD products (third row in Table 5) are limited to nadir observations. However, they may be extended to include limb products. These products are to be retrieved with the well-established and computationally effective DOAS algorithm.
These are essentially the algorithms developed for GOME but are extended to include windows in the SCIAMACHY IR regions. It is foreseen that the level 2 OL processor uses either DOAS or FURM in nadir, depending on the retrieved constituents. It is proposed that level 2 products for limb observations will use a technique similar to FURM. The level 2 OL products serve as a basis for all higher level and/or value added products, for example, interpolated and temporally averaged data and multisensor products based on SCIAMACHY and other ENVISAT instruments. 
TABLE 5. SCIAMACHY level 2 operational data products. Fast delivery (FD) products will be available within a few hours of spectrum acquisition. FD processing will employ lookup tables for radiative transfer rather than operational running of the models. Offline (OL) data products will be produced using improved ancillary data that become available after spectrum acquisition, for example, analyzed temperature and pressure fields.

\begin{tabular}{|c|c|c|c|c|c|c|}
\hline & \multicolumn{3}{|c|}{ Nadir total column amount } & \multicolumn{3}{|c|}{ Limb stratospheric profiles } \\
\hline & UV/Vis & IR & UV-IR & $\mathrm{UV} / \mathrm{Vis}$ & IR & UV-IR \\
\hline FD & $\begin{array}{l}\mathrm{O}_{3} \\
\mathrm{NO}_{2} \\
\mathrm{OCIO}^{\mathrm{a}} \\
\mathrm{SO}_{2}{ }^{\mathrm{a}} \\
\mathrm{H}_{2} \mathrm{CO}^{\mathrm{a}} \\
\mathrm{BrO}^{\mathrm{c}}\end{array}$ & $\begin{array}{l}\mathrm{H}_{2} \mathrm{O} \\
\mathrm{N}_{2} \mathrm{O} \\
\mathrm{CO} \\
\mathrm{CH}_{4}{ }^{\mathrm{b}}\end{array}$ & $\begin{array}{l}\text { Cloud } \\
\text { Aerosol }\end{array}$ & & & \\
\hline $\mathrm{OL}$ & $\begin{array}{l}\mathrm{O}_{3} \\
\mathrm{NO}_{2} \\
\mathrm{BrO} \\
\mathrm{OCIO}^{\mathrm{a}} \\
\mathrm{SO}_{2}{ }^{a} \\
\mathrm{H}_{2} \mathrm{CO}^{\mathrm{a}} \\
\mathrm{UV} \mathrm{Index}^{\mathrm{c}}\end{array}$ & $\begin{array}{l}\mathrm{H}_{2} \mathrm{O} \\
\mathrm{N}_{2} \mathrm{O} \\
\mathrm{CO} \\
\mathrm{CO}_{2} \\
\mathrm{CH}_{4} \\
\mathrm{p}, \mathrm{T}\end{array}$ & $\begin{array}{l}\text { Cloud } \\
\text { Aerosol }\end{array}$ & $\begin{array}{l}\mathrm{O}_{3} \\
\mathrm{NO}_{2}\end{array}$ & $\begin{array}{l}\mathrm{H}_{2} \mathrm{O} \\
\mathrm{CO}_{2} \\
\mathrm{CH}_{4} \\
\mathrm{p}, \mathrm{T} \\
\mathrm{N}_{2} \mathrm{O}^{\mathrm{c}} \\
\mathrm{CO}^{c}\end{array}$ & Aerosol \\
\hline
\end{tabular}

a Observed under special conditions (volcanic eruptions, ozone hole conditions, or tropospheric pollution) or after averaging.

${ }^{\mathrm{b}}$ Reduced quality product at $\mathrm{CO}$ fitting window.

${ }^{\mathrm{c}}$ Recommended by SCIAMACHY Science Advisory Group, implementation under negotiation with agencies.

To ensure high data quality over the mission lifetime, instrument performance will be monitored continuously and an intensive validation campaign will be performed at the beginning of the mission. Additionally, a longerterm validation by regularly performed balloon, aircraft, and satellite measurements over the whole mission lifetime is planned.

\section{Conclusions}

SCIAMACHY is a novel atmospheric remote sounding instrument, which will be launched as part of the ESA ENVISAT platform in 2000. SCIAMACHY will measure the extraterrestrial solar irradiance and the earthshine radiance in a variety of viewing geometries: (i) alternate nadir and limb viewing and (ii) solar and lunar occultation.

The inversion of SCIAMACHY measurements yields

1) the amounts and distributions of trace gases $\left(\mathrm{O}_{3}, \mathrm{O}_{2}\right.$, $\mathrm{O}_{2}\left({ }^{1} \Delta\right), \mathrm{O}_{4}, \mathrm{BrO}, \mathrm{OClO}, \mathrm{ClO}, \mathrm{SO}_{2}, \mathrm{H}_{2} \mathrm{CO}, \mathrm{NO}, \mathrm{NO}_{2}$, $\mathrm{NO}_{3}, \mathrm{CO}, \mathrm{CO}_{2}, \mathrm{CH}_{4}, \mathrm{H}_{2} \mathrm{O}, \mathrm{N}_{2} \mathrm{O}$ ) and aerosol,

2) pressure and temperature profiles,

3) cloud parameters (cloud cover, cloud-top height), and

4) surface spectral reflectance.

SCIAMACHY data products will be used for tropospheric and stratospheric research. The SCIAMACHY instrument will measure simultaneously and contiguously radiation in the wavelength range from 240 to $1750 \mathrm{~nm}$. In addition, it measures simultaneously in two shortwave infrared bands around 2.0 and $2.3 \mu \mathrm{m}$. From the limb and solar/lunar occultation atmospheric observations vertical distributions of the trace atmospheric constituents are derived. Limb observations provide in- formation about the mesospheric, the stratospheric, and the upper-tropospheric composition, yielding important information about stratospheric chemistry and physics as well as exchange between the stratosphere and troposphere. The combination of the near-simultaneous limb and nadir observations yields unique information about tropospheric and lower-stratospheric constituents (gases, aerosol, and clouds). SCIAMACHY is one of a limited number of instruments that are able to detect tropospheric constituents, such as $\mathrm{O}_{3}, \mathrm{NO}_{2}, \mathrm{BrO}, \mathrm{H}_{2} \mathrm{CO}$, $\mathrm{SO}_{2}, \mathrm{~N}_{2} \mathrm{O}, \mathrm{H}_{2} \mathrm{O}, \mathrm{CO}_{2}, \mathrm{CO}$, and $\mathrm{CH}_{4}$, in the lower troposphere down to the ground or the cloud top. Additionally, from the solar and lunar occultation measurements accurate profiles of atmospheric constituents are expected.

SCIAMACHY is intended to provide new insight into the global behavior of the troposphere and the stratosphere and is a good candidate instrument for any future global monitoring system. Its measurements and the data products retrieved from them are to be used for the study of a wide range of applications such as the impact of pollution, the response of the stratospheric chemistry to control strategies, and the assessment of global change.

Acknowledgments. SCIAMACHY is a national contribution to the ENVISAT mission funded by the German Aerospace Center (DLR) and the Netherlands Agency for Aerospace Programs (NIVR), including a contribution of the Belgian Institute for Space Aeronomy (BIRA-IASB). The SCIAMACHY industrial consortium comprises the prime contractors Dornier Satellite Systems (Germany) and Fokker Space (the Netherlands) and the subcontractors OHB-Systems 
(Germany), Jenoptik (Germany), Space Research Organisation Netherlands SRON (the Netherlands), TPD-TNO (the Netherlands), OIP (Belgium), and Epitaxx, Inc. (United States). The instrument and algorithm development is supported by the activities of the SCIAMACHY Science Advisory Group (SSAG), a team of scientists from various international institutions: University of Bremen (Germany), SRON (the Netherlands), Smithonian Astrophysical Observatory SAO (United States), BIRA-IASB (Belgium), MaxPlanck Institute for Chemistry in Mainz (Germany), KNMI (the Netherlands), University of Heidelberg (Germany), Institute for the study of Geophysical and Environmental Methodologies IMGA (Italy), and the Centre National pour la Recherche Scientifique CNRS-LPMA (France). Operational data processing is to be performed by the German Remote Sensing Data Center (DLR-DFD) within the ENVISAT ground segment. The mission operation is supported by the SCIAMACHY Operations Support Team SOST, which prepares mission scenarios, measurement strategies, and instrument calibration activities. The authors would like to thank H. Schrijver and I. Aben (SRON) for the provision of an update of the $\mathrm{CO} /$ $\mathrm{CH}_{4}$ sensitivity study (Schrijver et al. 1995) prior to publication. The authors would also like to thank two anonymous reviewers for their valuable comments. This work has been funded as part of the SCIAMACHY Scientific Support Study by the German Ministry of Education and Research (BMBF) under 50EP9207 and the University of Bremen.

\section{APPENDIX}

\section{The Satellite-Modified DOAS Equation for Two Instructive Cases}

For the case of long path measurements (Platt and Perner 1980), neglecting emission and assuming one absorber only, and that light is only scattered out of the beam, the amount of light at wavelength $\lambda$ reaching a detector, $I(\lambda)$, is given by

$$
I(\lambda)=I_{0}(\lambda) \exp \left[-\left(n_{a} \sigma_{a}^{*}(\lambda)+n_{r} \varepsilon_{r}+\sum_{p} n_{p} \varepsilon_{p}\right) s\right],
$$

where $I_{0}$ is the amount of light being emitted by a light source (lamp, sun, moon), $n_{a}$ is the concentration of the absorber, and $\sigma_{a}^{*}(\lambda)$ its absorption cross section. Here $n_{r}$ is the air density, $\varepsilon_{r}$ is the Rayleigh scattering cross section, $n_{p}$ is the concentration of scattering particles, $\varepsilon_{p}$ is the effective scattering cross section for particle scattering, and $s$ is the pathlength, which is independent of wavelength in this case. Splitting the absorption into two components, one which changes rapidly as a function of wavelength $\sigma_{a}(\lambda)$, called the differential absorption cross section, and one which varies only slowly with wavelength, $\sigma_{\text {slow }}(\lambda)$, the measured slant optical density is given as follows:

$$
\begin{aligned}
\tau(\lambda) & =-\ln \left(\frac{I(\lambda)}{I_{0}(\lambda)}\right) \\
& =\left(n_{a}\left(\sigma_{a}(\lambda)+\sigma_{\text {slow }}(\lambda)\right)+n_{r} \varepsilon_{r}+\sum_{p} n_{p} \varepsilon_{p}\right) s .
\end{aligned}
$$

The term $\left(n_{a} \sigma_{\text {slow }}(\lambda)+n_{r} \varepsilon_{r}+\Sigma_{p} n_{p} \varepsilon_{p}\right) s$ does not contain any narrow spectral features and, therefore, can be approximated by a low-order polynomial, $P(\lambda)$. Thus (A2) may be transformed into

$$
\tau(\lambda)-P(\lambda)=n_{a} \sigma_{a}(\lambda) s .
$$

When $N$ species having differential absorption cross sections interfering in a given spectral window, the DOAS fitting equation may be written as follows:

$$
\tau(\lambda)-P(\lambda)=\sum_{i=1}^{N} n_{a i} \sigma_{a i}(\lambda) s .
$$

Here $n_{a i} s$ represents the column density of the $i$ th molecule along the light path. Knowledge of the differential absorption cross section of all absorbers and the path length enables the concentrations of the absorbing species to be determined by a linear least squares fit of

$$
\left\|\tau(\lambda)-P(\lambda)-\sum_{i=1}^{N} n_{a i}(\lambda) \sigma_{a i} s\right\|^{2} .
$$

The fit parameters are the low-order polynomial coefficients and the column densities $n_{a i}$.

For nadir viewing geometry, the extraterrestrial solar irradiance impinging on the atmosphere, $F(\lambda)$, is modified during its passage through the earth's atmosphere by reflection at the surface, $R_{s}(\lambda)$; molecular absorption, $a_{i}(\lambda)$; Rayleigh and particle scattering, $S_{r}(\lambda)$ and $S_{p}(\lambda)$, respectively; and emission, $E_{i}(\lambda)$. The radiation leaving the top of the atmosphere, $I(\lambda)$, depends on the different physical processes occurring within the atmosphere:

$$
I(\lambda)=f\left(F(\lambda), R_{s}(\lambda), a_{i}(\lambda), S_{r}(\lambda), S_{p}(\lambda), E_{i}(\lambda)\right) .
$$

Solving Eq. (A6) requires the use of a radiative transfer model of the atmosphere that accurately describes all these processes.

For an understanding of the DOAS approach applied to nadir viewing geometry it is useful to consider the different rays reaching the instrument. To outline the physical principle behind DOAS two cases will be calculated explicitly in this appendix: (a) a single ray only reflected at the earth's surface and (b) rays of light scattered only once in the atmosphere, neglecting surface reflection. For simplicity an infinitely narrow instrument FOV is assumed and emission processes are neglected. 
Case a: Surface reflection only. Ignoring inelastic scattering processes, the radiance reaching the instrument due to light reflected at the earth's surface is given by

$$
\begin{aligned}
I_{1}(\lambda)= & A_{s}(\lambda) \pi^{-1} F(\lambda) \cos \vartheta_{0} \\
& \times \exp \left(-\int_{z_{0}}^{z_{\max }}(a(z)+b(z)) g\left(\vartheta, \vartheta_{0}\right) d z\right),
\end{aligned}
$$

with

$$
g\left(\vartheta, \vartheta_{0}\right) \equiv \frac{1}{\cos \vartheta}+\frac{1}{\cos \vartheta_{0}},
$$

total absorption coefficient:

$$
a(z) \equiv \sum_{i=1}^{N} n_{a i}(z) \sigma_{a i}(\lambda, z)
$$

and total scattering coefficient:

$$
b(z) \equiv n_{r}(z) \varepsilon_{r}+\sum_{p} n_{p}(z) \varepsilon_{p},
$$

with index $p$ for particulate scatterers and index $i$ for molecular absorbers.

Here $A_{s}(\lambda)$ is the spectral albedo of the surface, $z_{0}$ is the height of the earth's surface, $z_{\max }$ is the height of the top of the atmosphere, $\vartheta$ is the angle between the satellite line of sight and the local vertical at $z_{\max }$, and $\vartheta_{0}$ is the solar zenith angle. Equation (A8) holds under the assumption of a plane-parallel atmosphere. At high solar zenith angles $g\left(\vartheta, \vartheta_{0}\right)$ depends on the altitude due to the curvature of the atmosphere.

Using (A9) and the definition of slant scattering optical density

$$
\tau_{s c}(z) \equiv \int_{z}^{z_{\max }} b\left(z^{\prime}\right) g\left(\vartheta, \vartheta_{0}\right) d z^{\prime},
$$

the total slant optical density can be calculated as follows:

$$
\begin{aligned}
\tau_{1}(\lambda)= & -\ln \left(\frac{I_{1}(\lambda)}{F(\lambda)}\right) \\
= & \int_{z_{0}}^{z_{\max }}\left(\sum_{i=1}^{N} n_{a i}(z) \sigma_{a i}(\lambda, z)\right) g\left(\vartheta, \vartheta_{0}\right) d z \\
& +\tau_{s c}\left(z_{0}\right)-\ln \left(A_{s}(\lambda) \pi^{-1} \cos \vartheta_{0}\right) .
\end{aligned}
$$

Exchange of summation and integration and using the definition of the slant optical density $\mathrm{SOD}_{i}$ yields

$$
\begin{aligned}
\tau_{1}(\lambda)=\sum_{i=1}^{N} \operatorname{SOD}_{i}\left(z_{0}, \lambda\right)+\tau_{s c}\left(z_{0}\right) & \\
& -\ln \left(A_{s}(\lambda) \pi^{-1} \cos \vartheta_{0}\right)
\end{aligned}
$$

with
$\operatorname{SOD}_{i}(z, \lambda) \equiv \int_{z}^{z_{\text {max }}} \sigma_{a i}\left(z^{\prime}, \lambda\right) n_{a i}\left(z^{\prime}\right) g\left(\vartheta, \vartheta_{0}\right) d z^{\prime}$

The slant scattering optical density and the spectral surface reflection vary only slowly with wavelength and can be subtracted by a low-order polynomial, $P(\lambda)$. Thus (A13) can readily be transformed to the following equation:

$$
\tau_{1}(\lambda)=\sum_{i=1}^{N} \operatorname{SOD}_{i}\left(z_{0}, \lambda\right)+P(\lambda) .
$$

For modified DOAS, (A15) will be approximated by

$$
\tau_{2}(\lambda) \approx \sum_{i=1}^{N} k_{i} \operatorname{SOD}_{i}^{\bmod }\left(z_{0}, \lambda\right)+P(\lambda),
$$

and $k_{i}$ is ratio of the vertical column density $\mathrm{VCD}_{i}$ to be retrieved to the model vertical column density $\mathrm{VCD}_{i}^{\text {mod }}$,

$$
\begin{aligned}
k_{i} & =\frac{\mathrm{VCD}_{i}}{\operatorname{VCD}_{i}^{\text {mod }}} \\
\operatorname{VCD}_{i}(z) & =\int_{z}^{z \text { max }} n_{a i}(z) d z .
\end{aligned}
$$

The $\mathrm{VCD}_{i}$ and polynomial coefficients of $P(\lambda)$ are the fit parameters and $\mathrm{SOD}_{i}^{\text {mod }}$ is the calculated slant optical density for a representative model atmosphere.

Assuming that the absorption cross section is independent of altitude (i.e., it shows no temperature dependence) the $\mathrm{SOD}_{i}$ is directly related to the slant column density $\mathrm{SCD}_{i}$

$$
\operatorname{SOD}_{i}(z, \lambda)=\sigma_{a i}(\lambda) \operatorname{SCD}_{i}(z),
$$

with

$$
\operatorname{SCD}_{i}(z)=\int_{z}^{z_{\max }} n_{a i}\left(z^{\prime}\right) g\left(\vartheta, \vartheta_{0}\right) d z^{\prime} .
$$

The combination of (A15) and (A19) results in a form similar to the standard DOAS equation (1):

$$
\tau_{1}(\lambda)=\sum_{i=1}^{N} \sigma_{a i}(\lambda) \operatorname{SCD}_{i}\left(z_{0}\right)+P(\lambda) .
$$

Note that for this derivation we do not need the assumption of an optically thin medium. This approach can be transferred directly to the trace gas retrieval from occultation measurements.

Case b: Single scattering. For the treatment of singly scattered light we introduce the following definition of the number of scattering events at altitude $z$ :

$$
\chi(z)=\mathfrak{p}_{r} n_{r}(z) \varepsilon_{r}+\sum_{p} \mathfrak{p}_{p} n_{p}(z) \varepsilon_{p} .
$$

Here $\mathfrak{p}_{r}$ is the Rayleigh or molecular scattering phase function and $\mathfrak{p}_{p}$ is the particle scattering phase function.

Ignoring inelastic scattering processes, the radiance at the satellite is determined by single scattering events along the instrument's line of sight: 


$$
I_{2}(\lambda)=F(\lambda) \cos \left(\vartheta_{0}\right) \int_{z_{0}}^{z_{\max }} \chi(z) e^{-\tau_{s c}(z)} \exp \left[-\int_{z}^{z_{\max }} \sum_{i=1}^{N} n_{a i}\left(z^{\prime}\right) \sigma_{a i}\left(z^{\prime}\right) g\left(\vartheta, \vartheta_{0}\right) d z^{\prime}\right] d z
$$

Summation and integration in the last exponential factor can be exchanged:

$$
I_{2}(\lambda)=F(\lambda) \cos \left(\vartheta_{0}\right) \int_{z_{0}}^{z_{\max }} \chi(z) e^{-\tau_{s c}(z)} \exp \left[-\sum_{i=1}^{N} \int_{z}^{z_{\max }} n_{a i}\left(z^{\prime}\right) \sigma_{a i}\left(z^{\prime}\right) g\left(\vartheta, \vartheta_{0}\right) d z^{\prime}\right] d z .
$$

Using (see Bronstein and Semendjajew 1984)

$$
\int_{a}^{b} f(x) g(x) d x=g\left(x^{*}\right) \int_{a}^{b} f(x) d x, \quad a<x^{*}<b,
$$

it follows that

$$
\begin{aligned}
I_{2}(\lambda)= & F(\lambda) \cos \left(\vartheta_{0}\right) \\
& \times \exp \left(-\sum_{i=1}^{N} \int_{z^{*}}^{z_{\max }} n_{a i}\left(z^{\prime}\right) \sigma_{a i}\left(z^{\prime}, \lambda\right) g\left(\vartheta, \vartheta_{0}\right) d z^{\prime}\right) \\
& \times \int_{z_{0}}^{z_{\max }} \chi(z) e^{-\tau_{s c}(z)} d z,
\end{aligned}
$$

with

$$
z_{0}<z^{*}<z_{\max }
$$

Using the definition of the slant optical density (A14) we arrive at

$$
\begin{aligned}
I_{2}(\lambda)= & F(\lambda) \cos \left(\vartheta_{0}\right) \exp \left(-\sum_{i=1}^{N} \operatorname{SOD}_{i}\left(z^{*}, \lambda\right)\right) \\
& \times \int_{z_{0}}^{z_{\max }} \chi(z) e^{-\tau_{s c}(z)} d z .
\end{aligned}
$$

Defining

$$
R_{\mathrm{rel}}(\lambda):=\cos \left(\vartheta_{0}\right) \int_{z_{0}}^{z_{\max }} \chi(\lambda) e^{-\tau_{s c}(z)} d z
$$

the total slant optical density can be written

$$
\tau_{2}(\lambda)=-\ln \left(\frac{I_{2}(\lambda)}{F(\lambda)}\right)=\sum_{i=1}^{N} \operatorname{SOD}_{i}\left(z^{*}, \lambda\right)-\ln \left(R_{\mathrm{rel}}(\lambda)\right)
$$

The last term of the right-hand side varies only smoothly with wavelength (Rayleigh and Mie scattering) and can be subtracted by a low-order polynomial, $P^{\prime}(\lambda)$ :

$$
\tau_{2}(\lambda)=\sum_{i=1}^{N} \operatorname{SOD}_{i}\left(z^{*}, \lambda\right)+P^{\prime}(\lambda) .
$$

Again, for modified DOAS, the slant optical density can be approximated by

$$
\tau_{2}(\lambda) \approx \sum_{i=1}^{N} k_{i} \operatorname{SOD}_{i}^{\bmod }\left(z^{*}, \lambda\right)+P^{\prime}(\lambda),
$$

and $k_{i}$ is ratio of the vertical column density $\operatorname{VCD}_{i}$ to be retrieved to the model vertical column density $\mathrm{VCD}_{i}^{\text {mod }}$. Here $\mathrm{VCD}_{i}$ and polynomial coefficients of $P(\lambda)$ are the fit parameters and $\mathrm{SOD}_{i}^{\text {mod }}$ is the calculated slant optical density for a representative model atmosphere. Again, assuming that the absorption cross section is independent of the altitude (i.e., it shows no temperature dependence) and by using (A19), (A30) can be transformed to the standard DOAS form (1):

$$
\tau_{2}(\lambda)=\sum_{i=1}^{N} \sigma_{a i}(\lambda) \operatorname{SCD}_{i}\left(z^{*}\right)+P^{\prime}(\lambda) .
$$

For surface reflection and single scattering it has been demonstrated that the total slant optical density can be separated into differential and broadband parts, where the differential part contains the information about the slant or vertical column. In general, the instrument measures light from a combination of the different contributions (reflection, single and multiple scattering). Nevertheless, the approach of separating the differential optical density from the broadband part still holds, assuming that changing the absorber concentration does not change the light path (optical thin atmospheres). This results in the modified DOAS equation for the measured slant optical density $\tau_{\mathrm{s}}$ :

$$
\tau_{s}(\lambda) \approx \sum_{i=1}^{N} \frac{\mathrm{VCD}_{i}}{\operatorname{VCD}_{i}^{\text {mod }}} \operatorname{SOD}_{i}^{\bmod }\left(z^{*}, \lambda\right)+P^{\prime}(\lambda) .
$$

For standard DOAS the conversion of $\mathrm{SCD}_{i}$ to $\mathrm{VCD}_{i}$ will be performed by calculating the air mass factor with a radiative transfer model as described elsewhere (Solomon et al. 1987; Burrows et al. 1999). The remaining open point for modified DOAS, which yields the $\mathrm{VCD}_{i}$ directly, is the calculation of $\mathrm{SOD}_{i}^{\mathrm{mod}}$.

\section{Calculation of $\mathrm{SOD}_{i}^{\text {mod }}$}

In appendix $\mathrm{C}$ of Burrows et al. it is shown for an atmosphere with only one absorber that $\mathrm{SOD}_{i}^{\text {mod }}$ can be calculated as the ratio of simulated atmospheric radiance including all trace gases and a second simulation with the trace gas of interest excluded in the calculation. This can be generalized to multiple overlapping absorbers under certain conditions. In general, the total slant optical density of the $i$ th absorber (including nonabsorbing 
processes) can be defined as the difference of the logarithm of the backscattered radiance calculated with the $i$ th absorber removed, $I_{-i}^{\text {mod }}$, and the logarithm of the backscattered radiance including all relevant absorbers $I^{\text {mod }}$ for a model atmosphere with $\mathrm{VCD}_{i}^{\text {mod: }}$

$$
\tau_{i, s}(\lambda) \equiv \ln \left(I_{-i}^{\bmod }(\lambda)\right)-\ln \left(I^{\bmod }(\lambda)\right)=\ln \left(\frac{I_{-i}^{\bmod }(\lambda)}{I^{\bmod }(\lambda)}\right)
$$

Now it can be readily verified for the two cases (surface reflection, single scattering) discussed above that this definition yields directly the slant optical density of absorber $i$ for the model atmosphere: Applying (A34) to surface reflection only (case a), it can be shown, by inserting (A12) into (A34), that other contributions not related to the $i$ th absorber cancel out and (A34) yields the slant optical density of the $i$ th absorber $\mathrm{SOD}_{\mathrm{i}}$ without making any further assumptions. Here, the light path is well defined and independent of any absorber. This also holds for occultation measurements.

For the single scattering only (case b) the slant optical density can be calculated by inserting (A24) into (A34). Assuming that there exists a $z^{*}$ identical for all absorbers [cf. (A26)] the contributions from all remaining absorbers and scatters cancel out. This is equivalent with the assumption that the removal of the $i$ th absorber does not change the optical path (i.e., optical thin atmosphere). Equation (A33) yields then the slant optical density of the $i$ th absorber

$$
\tau_{i, s} \equiv \ln \left(\frac{I_{-i}^{\mathrm{mod}}}{I^{\mathrm{mod}}}\right)=\mathrm{SOD}_{i}^{\mathrm{mod}}
$$

In general, the model slant optical density $\mathrm{SOD}_{i}^{\text {mod }}$ will be calculated according to (A35) with a radiative transfer model, including multiple scattering and refraction when necessary. The influence of multiple scattering on this approximation is under investigation.

Combining (A33) and (A35) we arrive at the modified DOAS equation as presented in the main part of the paper (7) and the $\mathrm{VCD}_{i}$ will be obtained directly by a linear least squares fit of

$$
\left\|\tau_{s}(\lambda)-\sum_{i} \frac{\mathrm{VCD}_{i}}{\mathrm{VCD}_{i}^{\text {mod }}} \cdot \ln \left(\frac{I_{-i}^{\bmod }(\lambda)}{I^{\bmod }(\lambda)}\right)+\sum_{j} c_{j} \lambda^{j}\right\|^{2} .
$$

Fitted parameters are the vertical column density $\mathrm{VCD}_{i}$ and the polynomial coefficients $c_{j}$. Note that this approach allows an iterative solution to compensate for a possible dependence of $\mathrm{VCD}_{i}$ on $\mathrm{VCD}_{i}^{\bmod }$ or the model absorber profile. Model parameters can be varied and convergence is achieved if the retrieved $\mathrm{VCD}_{i}$ matches $\mathrm{VCD}_{i}^{\text {mod }}$.

\section{REFERENCES}

Anderson, G. P., and Coauthors, 1994: MODTRAN 3: Suitability as a flux-divergence code. Proc. 4th ARM Science Team Meeting, Charleston, SC, U.S. Department of Energy, 75-80.

Ashcroft, P., and B. Morel, 1995: Limits of space-based remote sensing for methane source characterisation. IEEE Trans. Geosci. Remote Sens., 33, 1124-1134.

Barth, C. A., D. W. Rusch, R. J. Thomas, G. H. Mount, G. J. Rottman, G. E. Thomas, R. W. Sanders, and G. M. Lawrence, 1983: Solar Mesosphere Explorer: Scientific objectives and results. Geophys. Res. Lett., 10, 237-240.

— W. W. Tobiska, and D. E. Siskind, 1988: Solar-terrestrial coupling: Low-latitude thermospheric nitric oxide. Geophys. Res. Lett., 15, 92-94.

Bhartia, P. K., R. D. McPeters, C. L. Mateer, L. E. Flynn, and C. Wellemeyer, 1996: Algorithm for the estimation of vertical ozone profiles from the backscattered ultraviolet technique. J. Geophys. Res., 101, 18 793-18 806.

Brewer, A. W., C. T. McElroy, and J. B. Kerr, 1973: Nitrogen dioxide concentrations in the atmosphere. Nature, 246, 129-133.

Bronstein, I. N., and K. A. Semendjajew, 1984: Taschenbuch der Mathematik. Verlag Harri Deutsch, 840 pp.

Burrows, J. P., and K. V. Chance, 1991: Scanning imaging absorption spectrometer for atmospheric chartography. Proc. SPIE, 1490, $146-155$.

- , and 1992: SCIAMACHY and GOME: The scientific objectives. Proc. SPIE, 1715, 502-512.

- , and Coauthors, 1988: SCIAMACHY-A European proposal for atmospheric remote sensing from the ESA Polar Platform. Max-Planck-Institut für Chemie, 95 pp. [Available from MaxPlanck-Institut für Chemie, 55122 Mainz, Germany.]

— V. V. Rozanov, Y. M. Timofeyev, A. V. Polyakov, R. J. D. Spurr, and K. V. Chance, 1992: A study of the accuracy of atmospheric trace gas vertical profile retreival from satellitebased occultation measurements. IRS Conference on Current Problems in Atmospheric Radiation 1992, S. Keevallik and O. Kärner, Eds., Deepak, 398-400.

—, D. Diebel, B. Kerridge, R. Munro, U. Platt, and H. Frank, 1994: A study of methods for retrieval of atmospheric constituents. Final Report under ESA Contract 9687/91/NL/BI, Serco Space Limited, Southall, United Kingdom. [Available from ESA/ESTEC Publication Division, P.O. Box 299, 2200 AG Noordwijk, the Netherlands.]

- E. Hölzle, A. P. H. Goede, H. Visser, and W. Fricke, 1995: SCIAMACHY - Scanning Imaging Absorption Spectrometer for Atmospheric Chartography. Acta Astronaut., 35, 445-451.

— , and Coauthors, 1999: The Global Ozone Monitoring Experiment (GOME): Mission concept and first scientific results. $J$. Atmos. Sci., 56, 151-175.

Chance, K. V., J. P. Burrows, and W. Schneider, 1991: Retrieval and molecule sensitivity studies for the Global Ozone Monitoring Experiment and the SCanning Imaging Absorption spectroMeter for Atmospheric Chartography. Proc. SPIE, 1491, 151-165.

—,- D. Perner, and W. Schneider, 1996: Satellite measurements of atmospheric ozone profiles, including tropospheric ozone, from ultraviolet/visible measurements in the nadir geometry: A potential method to retrieve tropospheric ozone. $J$. Quant. Spectrosc. Radiat. Transfer, 57, 467-476.

Chandra, S., C. H. Jackman, E. L. Fleming, and J. M. Russel III, 1997: The seasonal and long term changes in mesospheric water vapor. Geophys. Res. Lett., 24, 639-642

Chu, W. P., M. P. McCormick, J. Lenoble, C. Broniez, and P. Pruvost, 1989: SAGE II inversion algorithm. J. Geophys. Res., 94, 83398351.

Clough, S. A., F. X. Kneizys, L. S. Rothman, and W. O. Gallery, 1981: Atmospheric spectral transmittance and radiance: FASCOD1B. Proc. SPIE, 277, 152-166.

Crutzen, P. J., J.-U. Grooß, C. Brühl, R. Müller, and J. M. Russel III, 
1995: A reevaluation of the ozone budget with HALOE UARS data: No evidence for an ozone deficit. Science, 268, 705-708.

De Beek, R., R. Hoogen, V. V. Rozanov, and J. P. Burrows, 1997: Ozone profile retrieval from GOME satellite data I: Algorithm description. Proc. 3d ERS Symp., Florence, Italy, ESA, 749-754.

Dobber, M., 1996: SCIAMACHY Instrument Simulation Software Version 4.0, SRON-SCIA-IS-TR01, SCIA-IS-TR02, SCIA-ISTR03, SCIA-IS-TN04. Space Research Organization of the Netherlands. [Available from SRON, Sorbonnelaan 2, NL-3584 CA Utrecht, the Netherlands.]

Fishman, J., C. E. Watson, J. C. Larsen, and J. A. Logan, 1990: Distribution of tropospheric ozone determined from satellite data. J. Geophys. Res., 95, 3599-3617.

— , V. G. Brackett, E. V. Browell, and W. B. Grant, 1996: Tropospheric ozone derived from TOMS/SBUV measurements during TRACE A. J. Geophys. Res., 101, 24 069-24 082.

Frederick, J. E., and R. B. Abrams, 1982: Model studies of nitric oxide fluorescence in the Earth's backscattered spectrum. Planet. Space Sci., 30, 137-145.

Frerick, J., H. Bovensmann, S. Noël, J. P. Burrows, and M. Dobber, 1997: SCIAMACHY on-ground/in-flight calibration, performance verification and monitoring concepts. Proc. SPIE, 3117, $176-187$

Goede, A. P. H., R. W. M. Hoogeveen, R. J. van der A, and J. de Vries, 1993: Performance calculations and test of SCIAMACHY detector modules, optical remote sensing of the atmosphere Tech. Digest 1993, Vol. 5, Optical Society of America, Washington, DC, 436-439. [Available from Optical Society of America, 2010 Massachusetts Avenue NW, Washington, DC 200361023.]

—, P. de Groene, R. W. M. Hoogeveen, J. de Vries, R. J. van der A, C. Smorenburg, and H. Visser, 1994: SCIAMACHY instrument development for POEM-1. Adv. Space Res., 14, 17-20.

Grainger, J. F., and J. Ring, 1962: Anomalous Fraunhofer line profiles. Nature, 193, 762-762.

Guyenne, T. D., and C. J. Readings, Eds., 1993: GOME Interim Science Report. ESA/ESTEC SP-1151, 59 pp. [Available from ESA/ ESTEC Publication Division, P.O. Box 299, 2200 AG Noordwijk, the Netherlands.]

Heath, D. F., A. J. Krueger, H. A. Roeder, and B. D. Henderson, 1975 The solar backscatter ultraviolet and total ozone mapping spectrometer (SBUV/TOMS) for Nimbus G. Opt. Eng., 14, 323-331.

Hofmann, D. J., 1996: Recovery of Antarctic ozone hole. Nature, 384, 222.

Holton, J. R., P. H. Haynes, M. E. McIntyre, A. R. Douglass, R. B. Hood, and L. Pfister, 1995: Stratosphere-troposphere exchange. Rev. Geophys., 33, 403-439.

IPCC, 1996: Climate Change 1995: The Science of Climate Change. Cambridge University Press, $572 \mathrm{pp}$.

Joshi, A. M., G. H. Olsen, S. Mason, M. J. Lange, and V. S. Ban, 1992: Near-infrared $(1-3 \mu \mathrm{m})$ InGaAs detectors and arrays: Crystal growth, leakage current and reliability. Optical methods in atmospheric chemistry, Proc. SPIE, 1715, 586-593.

Kendall, M., and A. Stuart, 1979: The Advanced Theory of Statistics. Vol. 2. Charles Griffin and Company Ltd., 748 pp.

Kruizinga, B., C. Smorenburg, and H. Visser, 1994: Calibration concept of SCIAMACHY. Proc. SPIE, 2209, 196-209.

Mager, R., W. Fricke, J. P. Burrows, J. Frerick, and H. Bovensmann, 1997: SCIAMACHY - A new generation of hyperspectral remote sensing instrument. Spectroscopic Atmospheric Monitoring Techniques, K. Schaefer, Ed., SPIE, 84-94.

Mauldin, L. E., N. H. Zaun, M. P. McCormick, J. H. Guy, and W. R. Vaughn, 1985: Stratospheric aerosol and gas experiment II instrument: A functional description. Opt. Eng., 24, 307-321.

McCormick, M. P., P. Hamill, T. J. Pepin, W. P. Chu, T. J. Swissler, and L. R. McMaster, 1979: Satellite studies of the stratospheric aerosol. Bull. Amer. Meteor. Soc., 60, 1038-1046.

McPeters, R. D., 1989: Climatology of nitric oxide in the upper stratosphere, mesosphere, and thermosphere: 1979 through 1986. J. Geophys. Res., 94, 3461-3472.
Müller, R., P. J. Crutzen, J. U. Grooß, C. Brühl, J. M. Russell III, H. Gernandt, D. S. McKenna, and A. F. Tuck, 1997: Severe chemical ozone loss in the Arctic during the winter of 1995-1996. Nature, 389, 709-712.

Munro, R., R. Siddans, W. J. Reburn, and B. J. Kerridge, 1998: Direct measurement of tropospheric ozone distributions from space. Nature, 392, 168-171.

Newman, P. A., J. F. Gleason, R. D. McPeters, and R. S. Stolarski, 1997: Anomalously low ozone over the Arctic. Geophys. Res. Lett., 24, 2689-2692.

Platt, U., and D. Perner, 1980: Direct measurements of atmospheric $\mathrm{CH}_{2} \mathrm{O}, \mathrm{HNO}_{2}, \mathrm{O}_{3}, \mathrm{NO}_{2}$, and $\mathrm{SO}_{2}$ by differential optical absorption in the near UV. J. Geophys. Res., 85, 7453-7458.

Reber, C. A., C. E. Trevathan, R. J. McNeal, and M. R. Luther, 1993: The Upper Atmosphere Research Satellite (UARS) mission. $J$. Geophys. Res., 98, 10 643-10 647.

Richter, A., M. Eisinger, A. Ladstätter-Weißenmayer, and J. P. Burrows, 1998: DOAS zenith sky observations: 2. Seasonal variation

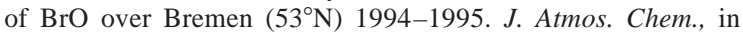
press.

Rodgers, C. D., 1976: Retrieval of atmospheric temperature and composition from remote measurements of thermal radiation. Rev. Geophys. Space Phys., 95, 5587-5595.

Rozanov, V. V., Y. M. Timofeyev, M. S. Biryulina, J. P. Burrows, R. J. D. Spurr, and D. Diebel, 1992: Accuracy of atmospheric constituent retrieval from multichannel remote sensing instruments. IRS Conference on Current Problems in Atmospheric Radiation 1992. S. Keevallik and O. Kärner, Eds., Deepak, 394-397.

— D. Diebel, R. J. D. Spurr, and J. P. Burrows, 1997: GOMETRAN: A radiative transfer model for the satellite project GOME, the plane-parallel version. J. Geophys. Res., 102, $16683-16695$.

—, T. Kurosu, and J. P. Burrows, 1998: Retrieval of atmospheric constituents in the UV visible: A new-quasi analytical approach for the calculation of weighting functions. J. Quant. Spectrosc. Radiat. Transfer, 60, 277-299.

Russell, J. M., III, and Coauthors, 1993: The Halogen Occultation Experiment. J. Geophys. Res., 98, $10777-10797$.

Sarkissian, A., H. K. Roscoe, and D. J. Fish, 1995: Ozone measurements by zenith-sky spectrometers: An evaluation of errors in Air Mass Factors calculated by radiative transfer models. $J$. Quant. Spectrosc. Radiat. Transfer, 54, 471-480.

Schrijver, H., S. Slijkhuis, M. G. M. Roemer, and A. P. H. Goede, 1995: Noise related limits on the detectability of concentration variations of $\mathrm{CH}_{4}$ and $\mathrm{CO}$ with SCIAMACHY. Atmospheric Sensing and Modeling, R. P. Santer Ed., SPIE, 39-46.

Shindell, D. T., D. Rind, and P. Logan, 1998: Increased polar stratospheric ozone losses and delayed eventual recovery owing to increasing greenhouse-gas concentrations. Nature, 392, 589592.

Singer, S. F., and R. C. Wentworth, 1957: A method for the determination of the vertical ozone distribution from a satellite. $J$. Geophys. Res., 62, 299-308.

Slijkhuis, S., 1994: SCIAMACHY/GOME Instrument Simulation Software-User's manual. SRON/SCIA/TR9302, SRON, Utrecht, the Netherlands, 53 pp. [Available from Space Research Organization of the Netherlands, Sorbonnelaan 2, NL-3584 CA Utrecht, the Netherlands.]

Solomon, S., A. L. Schmeltenkopf, and W. R. Sanders, 1987: On the interpretation of zenith sky absorption measurements. J. Geophys. Res., 92, 8311-8319.

Summers, M. E., and Coauthors, 1997: Implications of satellite OH observations for middle atmospheric $\mathrm{H}_{2} \mathrm{O}$ and ozone. Science, 277, 1967-1970.

Thomas, R. J., C. A. Barth, D. W. Rusch, and R. W. Sanders, 1984: Mesosphere Explorer Near-Infrared Spectrometer: Measurements of $1.27 \mu \mathrm{m}$ radiances and the inference of mesospheric ozone. J. Geophys. Res., 89, 9569-9580.

Timofeyev, Y. M., V. V. Rozanov, A. V. Pobezovski, and A. V. Poljk- 
ov, 1986: Multispectral method for the determination of vertical profiles of $\mathrm{O}_{3}, \mathrm{NO}_{2}$, and aerosol in the atmosphere. Meteor. Hydrol., 8, 66-73.

van $\operatorname{der}$ A, R. J., R. W. M. Hoogeveen, H. J. Spruijt, and A. P. H. Goede, 1997: Low noise InGaAs infrared $(1.0-2.4 \mu \mathrm{m})$ focal plane arrays for SCIAMACHY. Proc. SPIE, 2957, 54-65.
Weber, M., J. P. Burrows, and R. P. Cebula, 1998: GOME solar UV/VIS irradiance measurements between 1995 and 1997First results on proxy solar activity studies. Sol. Phys., 177, 63-77.

WMO, 1995: Global Ozone Research and Monitoring Project, scientific assessment of ozone depletion 1994. WMO Rep. 37. 